\title{
LA EVOLUCIÓN DE LA SOLUCIÓN DE CONTROVERSIAS EN EL MERCOSUR Y LA APLICACIÓN UNIFORME DE SUS NORMAS
}

\author{
José Miguel Olivares Tramón*
}

RESUMEN: La solución de controversias en el MERCOSUR se ha caracterizado por su constante evolución. El último tratado que la regula deja además abierta la posibilidad de nuevas reformas. Casi desde el comienzo se contempló la posibilidad de recurrir al arbitraje obligatorio entre los Estados miembros como forma definitiva para solucionar las controversias. Tampoco se descuidó la posibilidad de que los particulares pudiesen reclamar, aunque en forma muy limitada contra otros Estados miembros. Sin embargo, por mucho tiempo se utilizó un mecanismo informal de solución de las diferencias.

Desde que se convocó el primer tribunal arbitral se ba ido desarrollando una jurisprudencia que en especial ha clarificado en diferentes aspectos las obligaciones asumidas por los Estados miembros al incorporarse al MERCOSUR.

Otro aspecto relevante es la interpretación y aplicación que hacen los tribunales nacionales de las normas del MERCOSUR. Es una cuestión muy relevante para determinar la utilidad para los actores económicos privados de las normas del MERCOSUR. El tribunal permanente establecido recientemente se vinculará con dicha cuestión a través de la competencia para emitir opiniones consultivas, aunque de manera muy tímida en comparación a la experiencia europea.

Palabras Clave: Solución de controversias - MERCOSUR opiniones consultivas - Derecho internacional - tribunales nacionales.

\section{THE EVOLUTION OF THE DISPUTE SETTLEMENT AT THE MERCOSUR AND THE UNIFORM IMPLEMENTATION OF ITS RULES}

ABSTRACT: The solution of controversies in the MERCOSUR bas been characterized by its constant evolution. Besides, the last treaty that regulates it leaves open the possibility of new reforms. Almost since the beginning it was

Licenciado en Derecho de la Pontificia Universidad Católica de Chile (CHILE). Abogado. Doctor en Derecho (Europa-Institut, Sektion Rechtswissenschaft - Universidad del Sarre, Alemania). Profesor del Departamento de Derecho Internacional de la Pontificia Universidad Católica de Chile. Correo electrónico: jmolivares@uc.cl

Fecha de recepción: 8 de diciembre de 2006.

Fecha de aprobación: 14 de diciembre de 2006. 
contemplated the possibility to resort to obligatory arbitration among the member States as final form to solve the controversies. It was also not neglected the possibilities for individuals to demand (complain), although in a very limited form against other member States. Nevertheless, for a long time an informal mechanism of solution of the differences was utilized. Since the first arbitration court was called, a jurisprudence has been developing that especially bas clarified in different aspects the obligations assumed by the member States once incorporated to MERCOSUR.

Another prominent aspect is the national courts' interpretation and application of the norms of the MERCOSUR. It is a very relevant characteristic used to determine the utility for the private economic actors of the norms of the MERCOSUR. The recently established permanent court will be linked with the said characteristic through the competence to emit consultative opinions, although of very timid way in comparison to the European experience.

KEY WORDS: solution of controversies - MERCOSUR - consultive opinions - International Law - national courts

SUMARIO: I. Introducción. II. Evolución de los procedimientos de solución de controversias y reclamaciones en el MERCOSUR. III. Solución de controversias reservada a los Estados miembros del MERCOSUR. 1) Fase no judicial. 2) Fase arbitral. 2.1) Constitución del Tribunal Arbitral Ad Hoc. 2.2) Procedimiento y toma de decisiones del TAH. 2.3) El surgimiento de una jurisprudencia arbitral. 2.3.1) Determinación del Objeto de la Controversia. 2.3.2) Obstáculos No Tarifarios al Comercio. 2.3.2) Obstáculos No Tarifarios al Comercio. 2.3.3) Principios pacta sunt servanda y proporcionalidad. 2.3.4) Participación de Estados miembros que no son parte de la controversia. IV. Reclamaciones de personas naturales y jurídicas. 1) Inicio del procedimiento. 2) Procedimiento una vez que la reclamación ha sido acogida a tramitación. $V$. Solución de controversias ante la Comisión de Comercio del MERCOSUR. 5.1) El procedimiento de reclamación ante la Comisión de Comercio del MERCOSUR. 5.2) El procedimiento de consulta ante la CCM. VI. Aplicación de las normas del MERCOSUR por los tribunales nacionales. VII. El Tribunal Permanente de Revisión. 1) Composición del TPR. 2) Competencia del TPR. 3) El Procedimiento de Consulta. 4) Justificación del Procedimiento de Consulta. 5) Crítica al procedimiento de consulta. 6) Perspectivas del procedimiento de consulta. VIII. Conclusiones.

\section{INTRODUCCIÓN}

El Protocolo de Olivos (PO) es el segundo tratado en el marco del MERCOSUR que se ocupa de completamente de regular los procedimientos de solución de controversias. De sus normas se desprende además 
que no será el último ${ }^{1}$. Su principal contribución consiste en el establecimiento del Tribunal Permanente de Revisión (TPR) que actuará como tribunal revisor de cuestiones de Derecho tratadas en los laudos pronunciados por los tribunales arbitrales ad hoc, eventualmente como única instancia en la etapa arbitral del procedimiento de solución de diferencias y que a través de la competencia para emitir opiniones consultivas ha sido dotado de una importante función para el desarrollo de la interpretación uniforme de las normas del MERCOSUR.

La primera parte de este trabajo se ocupa de la evolución de los procedimientos de solución de controversias entre los Estados miembros del MERCOSUR desde sus inicios. Después se analizará la jurisprudencia arbitral que se ha ido desarrollando y que ha ido definiendo en mejor medida las obligaciones de los Estados miembros. El estudio seguirá con la descripción del procedimiento de reclamaciones para particulares y aquel cuya tramitación se inicia ante la Comisión de Comercio del MERCOSUR. Este órgano administró por varios años un procedimiento de solución de diferencias de carácter informal.

La presentación y el análisis del TPR son precedidos del estudio de la aplicación e interpretación de las normas del MERCOSUR por los tribunales nacionales. Se quiere realzar de ese modo la importancia que tiene la existencia de un procedimiento que vincule a la jurisdicción internacional como la del TPR con los jueces nacionales. A partir de ello es que se fundamente la insuficiencia del procedimiento de consulta, tal como ha sido concebida hasta ahora, sin perjuicio de considerarlo una contribución para el desarrollo de la interpretación y aplicación uniforme de las normas del MERCOSUR.

\section{EVOLUCIÓN DE LOS PROCEDIMIENTOS DE SOLUCIÓN DE CONTRO- VERSIAS Y RECLAMACIONES EN EL MERCOSUR}

Con la firma del Tratado de Asunción ${ }^{2}$ de 1991 (TA) Argentina, Brasil, Paraguay y Uruguay formalizaron su intención de constituir un Mercado Común entre los mencionados Estados. El breve texto del TA ${ }^{3}$

Véase infra nota a pie de página n. 13.

El Tratado para la Constitución de un Mercado Común fue firmado en Asunción el 26/ $3 / 1991$ y entró en vigencia el 29/11/1991.

3 El TA se compone de un preámbulo y seis capítulos que en total contienen veinticuatro artículos. Además tiene cinco anexos. El primero contiene el programa de liberalización comercial, el segundo establece las reglas de origen, el tercer anexo establecía un mecanismo provisorio de solución de controversias, el cuarto regulaba las medidas de salvaguardia y el quinto instituía grupos especiales de trabajo. La brevedad del TA se hace más patente si se compara su contenido con el del Tratado constitutivo de la Comunidad Económica Europea (TCEE), hoy en día conocido como Tratado de la Comunidad Europea (TCE), que fue firmado el $25 / 3 / 1957$ en Roma y que también tenía por fin la creación de un mercado común. 


\section{refleja por una parte el cambio de paradigma económico en Argentina y} Brasil y su efecto en la estrategia de integración económica de ambos países $^{4}$. Por otra parte el TA es la consolidación de un camino de entendimiento entre las dos economías más grandes de Sudamérica ${ }^{5}$ que había empezado en la década de 1970 y que dejo atrás una relación de rivalidad entre ambos países ${ }^{6}$.

4 Los gobiernos de ambos países habían sido muy reticentes a aplicar las reformas económicas de carácter ortodoxo propuestas por los organismos multilaterales de crédito para enfrentar la crisis de la deuda externa que afectó a la mayoría de los países de América Latina desde la primera mitad de la década de 1980. Solo como consecuencia del fracaso de las medidas económicas aplicadas para poder servir el pago de la deuda externa, nuevos gobiernos en ambos países comenzaron a aplicar políticas de ajuste económico basadas en la apertura comercial y desregulación económica. Este cambio facilitó la integración económica entre ambos países, que en el pasado se había caracterizado en reducciones arancelarias puntuales y proyectos industriales conjuntos, y que además era concebida como una integración económica abierta a la economía global.

La apertura y liberalización económica se refleja en la integración económica entre ambos países por primera con la firma del Acta de Buenos Aires de 1991. Ella menciona por primera vez el objetivo de crear un mercado común sobre la base de reducciones arancelarias lineales y automáticas ( $\mathrm{N}^{\circ} 2$ del acta mencionada), aunque sin mencionar plan concreto para ir materializando la liberalización del comercio entre ambos países. Con la firma del TA se incorporan Paraguay y Uruguay al proyecto de creación de un mercado común entre Argentina y Brasil, cuestión que se explica por los vínculos económicos ya existentes y por la utilidad del proyecto para la estabilización de las reformas económicas y la democracia en Paraguay y Uruguay.

Con la creación del MERCOSUR, todos los Estados partes, pero especialmente los más grandes, esperaban fortalecer los efectos positivos de las reformas económicas liberalizadoras, aumentando su competitividad y atractivo como receptores de inversión extranjera, por medio de economías de escala y de especialización económica. En lo interno el proyecto del mercado común servía de legitimación de las reformas económicas liberalizadoras y hacia los actores económicos transnacionales como señal de continuidad de esas reformas. No se debe descartar como incentivo para a creación del MERCOSUR la necesidad de fortalecer la posición negociadora de sus Estados miembros ante la creación de un área del libre comercio entre Canadá y EUA, la renovada fuerza de la Comunidad Europea en torno al proyecto de creación del Mercado Interior el 1 de enero de 1993 y la ausencia de avances en esa época en torno a la Ronda de Uruguay del GATT (a este respecto $c f r$. FILHO, Calixto / SAmTlebeN, Jürgen; "Der Südamerikanische Gemeinsame Markt. Eine rechtliche Analyse des MERCOSUR. Teil I, Wertpapier Mitteilungen -Zeitschrift für Wirtschafts- und Bankrecht, $\mathrm{Nr} .33$ (1992), p. 1347, incluido pie de página $\mathrm{N}^{\circ}$ 39; FISCHER, Thomas, "MERCOSUR - Eine Zwischenbilanz" en Bendel, Petra/Fischer, Thomas (eds.), Wie erfolgreich ist der MERCOSUR? -Das südamerikanische Bündnis aus interdisziplinärer Sicht (Verlag für Entwicklungspolitik, Saarbrücken, 1999) p. 14; SCHIRM, Stefan A., Globale Märkte, nationale Politik und regionale Kooperation in Europa und den Amerika (Nomos, Baden-Baden, 1999, pp. 134-161 y SCHIRM, Stefan A., Kooperation in den Amerikas: NAFTA, MERCOSUR und die neue Dynamik regionaler Zusammenarbeit (Nomos, Baden-Baden, 1997) pp. 82-84 y 105).

5 Cfr. Naciones Unidas - CEPAL, 2004 Anuario Estadístico de América Latina y el Caribe (Naciones Unidas, Santiago de Chile, 2005) pp. 194-195.

6 Históricamente Argentina y Brasil rivalizaron a causa de la competencia entre ambos por el poder de influencia de cada uno en Sudamérica. En un ambiente de mayor confianza mutua a partir de finales de la década de 1970 se soluciona por medio del Acuerdo Tripartito de 19/10/1979 la controversia surgida respecto del curso superior del Río 
Después de haberse superado el período que va desde enero de 1999 hasta comienzos de 2002, considerada una de las etapas más críticas del MERCOSUR ${ }^{7}$, sus Estados miembros acordaron en el año 2003 el Protocolo de Olivos (PO). Este tratado es el nuevo cuerpo normativo que regla los procedimientos de solución de controversias entre sus Estados miembros y las reclamaciones que pueden hacer valer particulares contra los Estados miembros. El primer tipo de controversias nunca ha dejado de estar regulada, pero ha evolucionado progresivamente en su complejidad. Originalmente se estableció en un anexo del TA un mecanismo que contemplaba las negociaciones directas entre los Estados miembros involucrados en la controversias y la posterior intervención del Grupo Mercado Común (GMC) así como del Consejo del Mercado Común (CMC), en caso que no se hubiese alcanzado una solución de la respectiva controversias en las etapas anteriores. Este primer procedimiento de solución de controversias, que nunca fue utilizado por los Estados miembros mientras estuvo en vigor, fue establecido de manera transitoria y debía ser reemplazado por un mecanismo para el período de transición ${ }^{8}$. Los Estados

Paraná que se había originado con la construcción de la Represa de Itaipú, se celebran una serie de acuerdos en el ámbito de la energía nuclear, para la utilización de la parte en común del Río Paraná, para la conexión de los sistemas eléctricos de ambos países y el intercambio de experiencias para el desarrollo de fuentes de energía no tradícionales. Este curso de acercamiento es continuado por los primeros gobiernos democráticos de ambos países durante la década de 1980 lo que se refleja en la Declaración de Iguazú de 30/11/ 1985 así como en el Acuerdo sobre el Programa de Integración y Cooperación Económica (PICE) de 10/11/1986 ( $C f r$ r. NOHLEN, Dieter; FernándeZ BAEZA, Mario, "Cooperación y Conflicto. Concepto y procesos en la Cuenca del Plata "en NoHLen, Dieter et al. (eds.), Kooperation und Konflikt im La-Plata-Becken (Breitenbach, Saarbrücken, 1986), p. 73; Nohlen, Dieter/Fernández BaezA, Mario, "Die Entwicklung der argentinisch-brasilianischen Beziehungen in den 70er Jahren: vom Konflikt zur Kooperation" en NOHLEN, Dieter et al. (eds.), Kooperation und Konflikt im La-Plata-Becken (Breitenbach, Saarbrücken, 1986), p. 329.) y ALMEIDA Mello, Leonel Itaussu, Brasil y Argentina en perspectiva: competencia, distensión e integración, pp. 291-302 (en línea). [fecha de consulta: 28 de junio de 2006]. Disponible en: <http://168.96.200.17/ar/libros/filopol2/mello.pdf>

7 Esta etapa se sitia temporalmente entre enero de 1999 y el mismo mes de 2002, que es el período que va desde la devaluación de la moneda brasileña y la devaluación de la moneda argentina que puso fin al tipo de cambio fijo en ese país. Durante aquel tiempo se puso en duda la meta de constituir un mercado común y se propuso flexibilizar los compromisos asumidos por los Estados miembros para alcanzar el mencionado objetivo (Cfr. Gratius, Susanne, "Warum stagniert der Mercosur? Die politisch-institutionelle Dimension der Krise“, en Lateinamerika Analysen 1 (2002), pp. 139-140; PREUSSE, Heinz, "Warum stagniert der MERCOSUR? Wirtschaftliche Faktoren" en Lateinamerika Analysen 1 (2002), p. 133, TACCONE, Juan Josél NOGUEIRA, Uziel (eds.), Informe MERCOSUR N 6 Perídodo 1999-2000 (BID-INTAL, Bs. Aires, 2000) pp. 25-28, TACCONE, Juan Josél NogueIra, Uziel (eds.), Informe MERCOSUR $N^{\circ} 7$ Período 2000-2001 (BID-INTAL, Bs. Aires, 2001) pp. 1-7 TACCONE, Juan José/Nogueira, Uziel (eds.), Informe MERCOSUR $N^{\circ} 8$ Período 2001-2002 (BID-INTAL, Bs. Aires, 2003) p. 45).

8 De acuerdo al Art. 3 TA se entendía por período de transición el lapso entre la entrada en vigor del TA y el 31 de diciembre de 1994. Durante este período debían darse los primeros pasos para la constitución de un mercado común, los que a la luz del Art. 5 
miembros se dieron las reglas sobre solución de controversias para el período de transición por medio del Protocolo de Brasilia (PB), cuyas reglas están inspiradas en los procedimientos de solución de controversias contemplados en el TLCAN, en la OMC y que se diseñaron para la ALALC $^{9}$. Este preveía en la tercera etapa del procedimiento de solución de controversias la posibilidad de convocar un tribunal arbitral ${ }^{10}$. Adicionalmente el PB instauró un procedimiento para tramitar reclamaciones hechas por particulares.

El Protocolo de Ouro Preto (POP) extendió la vigencia de las reglas del PB más allá del período de transición ${ }^{11}$ e hizo depender la creación de un sistema permanente de solución de controversias del término del proceso de armonización del Arancel Externo Común (AEC) ${ }^{12}$. Además el POP complementó los procedimientos previstos en el PB mediante la creación de un procedimiento para la tramitación de controversias entre los Estados parte o de reclamaciones sobre cuestiones relativas a los instrumentos de política comercial del MERCOSUR. Dicho procedimiento

TA eran la realización del Programa de Liberalización Comercial, la coordinación gradual de las políticas macroeconómicas y de manera convergente con la eliminación de las restricciones arancelarias y no arancelarias, acordar un arancel externo común y acuerdos sectoriales para "optimizar la utilización y movilidad de los factores de producción”. En la práctica, a través del Programa de Liberalización Comercial, solo regló la reducción arancelaria, quedando excluidos de esta una parte menor de las posiciones arancelarias, las que sin embargo representaban una parte importante del valor total del comercio intrazonal. Tampoco se reguló la eliminación de las restricciones no arancelarias, las que han sido fuente permanente de conflictos entre los Estados miembros. Hasta el día de hoy no se puede hablar de una completa liberalización comercial en el MERCOSUR. El Arancel Externo Común se reguló a través del Acuerdo sobre Aranceles Comunes, que entró en vigencia el 1 de enero de 1995. El término "Unión Aduanera Imperfecta" que se usa para describir el estado actual de evolución del MERCOSUR describe claramente que aún no está incluido todo el universo arancelario. Véase PEÑA, Félix, Mercosur: Análisis de una Década y Tendencias bacia el Futuro (en línea). Mayo de 2001 [fecha de consulta: 30 de junio de 2006]. Disponible en: http:// webudesa.udesa.edu.ar/departamentos/economia/mariano_tommasi/cedi/dts/dt50.PDF, p. 11; Preusse (n. 6), p. 126-127; TACCONE/ NOGUeira: "Informe Nr. 6" (n. 6), pp. 25, 58, 61-63 y TACCONE/Nogueira: “Informe $\mathrm{N}^{\circ}$ 8" (n. 6), pp. 89, 104-105 y WEHNER, Ulrich, Der Mercosur - Rechtsfragen und Funktionsfähigkeiten eines neuartigen Integrationsprojektes und die Erfolgsaussichten der interregionalen Kooperation mit der Europäischen Union (Nomos, Baden-Baden, 1999), pp. 150-155.

TAYLOR, Cherie O'Neall, "Dispute Resolution as a Catalyst for Economic Integration and a Agent for Deeping Integration: NAFTA and MERCOSUR?" en Northwestern Journal of International Law and Business, Vol. 17, $\mathrm{n}^{\circ} 2 / 3$ (1996), p. 873 y Laudo $\mathrm{N}^{\circ}$ 2/2006 de 6/9/2006, párrafo 163).

Arts. 7.1 y 32 PB.

Art. 43 POP.

Art. 44 POP. La existencia de un AEC y un sistema de solución de controversias son cuestiones de naturaleza distinta, por eso se ha considerado su vinculación como una situación "curiosa". Cfr. SAMTLeben, Jürgen, "Der MERCOSUR als Rechtssystem" en BASEDOW, Jürgen/ SAMTLEBEN, Jürgen (eds.), Wirtschaftsrecht des MERCOSUR - Horizont 2000, Baden-Baden, 2002, pp. 84-86. 
se tramita en la etapa no arbitral básicamente frente a la comisión del MERCOSUR (CCM).

El PO, que derogó el PB y no se considera asimismo como el instrumento que contiene el sistema permanente de solución de controver$\operatorname{sias}^{13}$, mantiene los procedimientos para solución de controversias contemplados en el PB y en el POP, esto es, un procedimiento para la solución de controversias entre Estados miembros, otro para la tramitación de reclamaciones hechas por personas naturales o jurídicas y otro para las reclamaciones de Estados y personas naturales o jurídicas que se refieren al ámbito de competencia de la CCM. Todos los procedimientos mencionados permiten que se solicite la constitución del Tribunal Arbitral Ad Hoc (TAH). El PO ha fortalecido el rol de los tribunales arbitrales, ya que a diferencia del PB después de la fase de negociaciones directas entre los Estados involucrados en la controversia o reclamación, la intervención del GCM o de la CCM solo es procedente si así lo acuerdan los Estados envueltos en la disputa. Sin ese acuerdo, cualquiera de los Estados miembros puede solicitar la constitución del TAH. Además se contempla la posibilidad de recurrir ante el Tribunal Permanente de Revisión, el cual puede ser también puede ser convocado como tribunal arbitral de única instancia cuando así lo acuerden las partes.

Las controversias entre algún Estado miembro y los órganos del MERCOSUR así como entre estos últimos no están contempladas en el $\mathrm{PO}^{14}$. Lo anterior se explica porque en los órganos decisorios del MERCOSUR están representados todos los Estados miembros y se toman las decisiones por consenso, lo cual hace difícil imaginar que algún Estado miembro plantee una controversia a alguno de los órganos deciso$\operatorname{rios}^{15}$. Tampoco pueden plantearse conflictos entre los órganos decisorios, porque entre estos últimos existe una estructura jerárquica en cuya cumbre se encuentra el CMC que está conformado entre otros por los presidentes de cada uno de los Estados ${ }^{16}$, lo cual, considerando el carácter presidencialista de las formas de gobierno de esos países y de la región en general, no deja lugar a dudas sobre el orden jerárquico mencionado.

13 El Art. 53 PO mantiene el vínculo entre la creación del sistema permanente de solución de controversias con el establecimiento del AEC.

14 OPERTTI BADÁN, Didier, "Sistema de resolución de controversias en el MERCOSUR" en Kleinheisterkamp, Jan/Lorenzo Idiarte, Gonzalo A. (coords.), Avances del derecho internacional privado en América Latina - Liber Amicorum Jürgen Samtleben, Montevideo, 2002 , pp. 457-459.

15 LAVRANOS, Nikolaus, "An Introduction into the Regional Economic Integration Process of the Ameritas" en Zeitschrift für europarechtliche Studien, Vol. 4 n. 1 (2001), p. 127 y. SAmTleben, Jürgen, "Las Perspectivas para un Tribunal del MERCOSUR y la experiencia europea” en Jurisprudencia Argentina, Tomo I (1998), pp. 796-798.

16 Alonso García, Ricardo, Tratado de Libre Comercio, Mercosur y Comunidad Europea - Solución de controversias e interpretación uniforme (McGraw-Hill, Madrid, 1997), pp. 59-60. 


\section{SOLUCIÓN DE CONTROVERSIAS RESERVADA A LOS ESTADOS MIEM- BROS DEL MERCOSUR}

El PO considera que las controversias entre Estados miembros del MERCOSUR son aquellas que se refieren a la interpretación, aplicación o incumplimiento del TA, del PO, de los protocolos y acuerdos celebrados en el marco del TA así como las restantes fuentes normativas en el MERCOSUR ${ }^{17}$. El procedimiento para resolver esas controversias está dividido en una etapa extrajudicial o diplomática y una etapa arbitral.

En el tercer procedimiento arbitral de que conoció el TAH debieron los árbitros pronunciarse sobre el concepto de "controversia" y cuando esta debía ser resuelta conforme a las normas del MERCOSUR sobre solución de controversias ${ }^{18}$. En este caso, una de las partes alegaba que el TAH era incompetente dado que ninguna norma del MERCOSUR era aplicable a la cuestión jurídica planteada. Sobre la base de jurisprudencia internacional ${ }^{19}$ se resolvió que el TAH era competente para conocer cualquier diferencia de opinión entre Estados miembros sobre la existencia o inexistencia de obligaciones amparadas por la normativa del

Art. 1.1 PO. Las fuentes normativas de los órganos decisorios del MERCOSUR son las decisiones, las resoluciones y las directivas. Estos son adoptadas por el CMC, GMC y la CCM respectivamente. Su diferente denominación se debe exclusivamente al órgano del cual emanan y de las competencias que este tiene atribuidas. Todas tienen la misma naturaleza jurídica, esto es, son normas de Derecho Internacional Público que requieren ser incorporadas en los ordenamientos jurídicos nacionales de los Estados miembros (Véase WeHNER (n. 8), pp. 94-95; OPERTTI BADÁN (n. 14), p. 465 y GARNELO, Vicente, Evolución institucional y jurídica del MERCOSUR (BID-INTAL, Buenos Aires, 1997), p. 12. En ese momento estaba vigente el PB, pero el pronunciamiento del tribunal arbitral ad hoc sigue estando vigente bajo el PO, dado que se trata en el fondo del mismo ámbito de aplicación. El Art, 1 del PO solo actualiza el contenido del Art. 1 del PB, manteniendo el mismo concepto de controversia.

19 El tercer laudo arbitral de 10/3/2000 en la sección II A, pies de página 1-6, nos recuerda que en el Caso Mavrommatis (CPIJ, Serie A, $\mathrm{N}^{\circ} 2$, p. 11) la Corte Permanente de Justicia Internacional (CPJI) sostuvo que una controversia es "un desacuerdo sobre un punto de vista de Derecho o de hecho, un conflicto de opiniones legales o intereses entre las partes". El tribunal ad hoc indica que el concepto de controversia mencionado fue recogido por la Corte Internacional de Justicia (CIJ) en el caso Camerún Septentrional (ICJ Reports 1963, p. 27), en el caso sobre Aplicabilidad de la obligación de arbitraje en virtud de la Sección 21 del Acuerdo de 26 de junio de 1947 relativo a la sede de la ONU (ICJ Reports 1988, p. 27 párrafo 35) y en el caso de Timor Oriental (ICJ Reports 1995, p. 99). En Ia misma línea el Tercer Tribunal Arbitral ad hoc del MERCOSUR agrega que la CIJ en el caso África Sudoccidental (ICJ Reports 1962, p. 328) sostuvo que para determinar la existencia de una controversia hay que demostrar que el reclamo de una de las partes se opone positivamente al de la otra y que en un informe de los Directores Ejecutivos del Banco Mundial (Doc. ICSID/2 de marzo de 1965, p. 9 para $26^{\circ}$ Report of the Executive Directors of the Internationl Bank for Reconstruction and Development on the Convention on the Setlement of Investments Disputes between States and Nacional of other States) se afirmó que controversia internacional es aquella concerniente a la existencia o no de un derecho o de una obligación. 
MERCOSUR. Lo anterior significa que basta con que haya una diferencia de apreciación sobre una cuestión de Derecho para que exista una controversia, siendo por tanto lo relevante que haya puntos de vista contradictorios $^{20}$. El IV laudo arbitral confirmó el punto de vista de su antecesor y agregó de manera complementaria que la existencia o inexistencia de una controversia debe ser determinada de manera objetiva, no siendo por ello suficiente para determinarlo que una de las partes alegue la inexistencia de la disputa ${ }^{21}$. Siguiendo jurisprudencia desarrollada a través de procedimientos de solución de controversias ventilados ante la OMC, en al menos dos laudos de los tribunales del MERCOSUR, ha quedado establecido que el objeto de la controversia desaparece cuando se pone fin a la acción u omisión de un Estado miembro que ha sido impugnada como incompatible con las normas del MERCOSUR. Eso ocurre cuando por ejemplo es derogada la norma nacional impugnada o cuando se termina con la omisión de las conductas necesarias para cumplir con las normas del MERCOSUR 22 .

Siguiendo el ejemplo de otros acuerdos comerciales ${ }^{23}$, el PO contempla una forum option para las controversias interestatales, de tal modo que el Estado demandante o ambas partes de mutuo acuerdo pueden someter

BAARS, Alf, "Kommentar zum 3. Schiedsspruch" en BASEdow/ SAmtleben (n. 12), pp. 303-305. El X Laudo Arbitral de 5/9/2005 en el último párrafo de la sección titulada "Derecho aplicable" reafirma que para determinar la existencia de una controversia debe existir un desacuerdo o diferencia de puntos de vista. IV laudo arbitral de 21/5/2001 párrafos 102-103.

22 Véase X Laudo Arbitral de 5/8/2005, sección titulada "Las comunicaciones de las Partes respecto a la terminación de la controversia y Laudo $\mathrm{n}^{\circ}$ 2/2006, párrafos $78-79$ (incluida la nota a pie de página $\mathrm{n}^{\circ} 1$ ).

23 Por ejemplo el procedimiento general de controversias contemplado en el Capítulo XX del Tratado de Libre Comercio de América del Norte (TLCAN) contempla la opción de foro, pero con un carácter más restrictivo, ya que también debe ser notificado de la reclamación el tercer Estado miembro, el que puede en caso de desacuerdo hacer prevalecer el procedimiento general de solución de controversias del TLCAN. Además de acuerdo al Art. 2005 párrafo 6 TLCAN, la parte demandada puede pedir por escrito que se examine la controversia de acuerdo a los procedimientos del TLCAN cuando esta se refiera a ciertas materias específicas como la protección medioambiental o de la salud. La opción de foro se encuentra en la mayoría de los tratados de libre comercio (TLC) o acuerdos de complementación económica (ACE) suscritos por Chile. Las cláusulas acordadas se diferencian básicamente en las restricciones que se imponen a la forum option, e.g. el TLC entre Canadá y Chile así como entre este último país y México la parte demandada también puede pedir por escrito que la controversia se resuelva de acuerdo a los TLC respectivos cuando se refiera a una materia regulada por tratados medio ambientales (arts. N-05.2 y 18-03.3 respectivamente). Una limitación de distinta naturaleza es la del Art. 2 del XXI. Protocolo Adicional del ACE n. 35 entre Chile y el MERCOSUR, conforme a la cual se puede optar entre las reglas de solución de controversias de ese protocolo o de la OMC cuando el litigio se refiera a medidas compensatorias o antidumping.

En el TLCAN (Art. 2005) también está previsto que una vez iniciado el procedimiento para la solución de una controversia ante cualquiera de los foros posibles quedan excluidos los demás. 
la controversia ya sea a las reglas del PO o al procedimiento de solución de controversias de la Organización Mundial del Comercio (OMC) o de otros acuerdos internacionales de carácter comercial del que sean parte los Estados miembros del MERCOSUR. La opción por cualquiera de los foros mencionados impide la presentación simultánea o posterior del caso en cuestión ante cualquiera de las otras instancias ${ }^{24}$. Este efecto vinculante de la forum option es considerada una reacción a la conducta de un Estado miembro del MERCOSUR que no estuvo de acuerdo con un laudo arbitral del TAH, presentando la misma controversia ante el Órgano de Solución de Controversias de la OMC (OSD) ${ }^{25}$.

Una regulación más detallada de la forum option es hecha por el Reglamento del Protocolo de Olivos (RPO). Conforme a esas disposiciones la Parte reclamante debe notificar al Estado miembro reclamado la decisión de plantear la controversia ante un mecanismo distinto del establecido en el PO. A partir de la fecha de la notificación hay quince días para que las partes acuerden llevar la controversia a un foro distinto. Si no hay acuerdo, prevalecerá la opción del Estado reclamante, el cual deberá notificársela al Estado miembro reclamado y al Grupo Mercado Común ${ }^{26}$. Se entiende que se ha iniciado el procedimiento conforme a las reglas del PO cuando se han iniciado negociaciones directas en una controversia interestatal o consultas como consecuencia de la reclamación de un particular entre los Estados involucrados en la controversia ${ }^{27}$. Asimismo se presume la opción por el procedimiento de solución de controversias de la OMC cuando se ha solicitado la conformación de un grupo especial ante el $\mathrm{OSD}^{28}$.

25 En concreto se trata de la controversia planteada por Brasil en contra de medidas antidumping aplicadas por Argentina. Al no quedar Brasil conforme con lo resuelto por el laudo del Tribunal Arbitral ad hoc de 21/5/2001 este Estado sometió el asunto ante el Órgano de Resolución de Controversias de la OMC. Véase PASTORI, Alejandro, Los regímenes de solución de controversias en el marco de la ALADI y su articulación con otros sistemas de solución de controversias, en particular el existente en la OMC en VIII Seminario Jurídico: "La Dimensión Jurídica de la Integración" celebrado el 2 y 3 de octubre de 2003 en Rosario, Argentina (en línea), 2 de octubre de 2003 [fecha de consulta: 13 noviembre 2006]. Disponible en: <http://www.aladi.org/nsfaladi/reuniones.nsf/6053654be7953f91032569fa0064855b/ 0b286a2719a2287703256ebb006988bc?OpenDocument> y TACCONE, Juan Josél NoGUEIRA, Uziel (eds.), Informe MERCOSUR $N^{\circ} 8$ Periodo 2001-2002 (BID-INTAL, Bs. Aires, 2003), p. 101.

Art. 1.1 RPO.

Art. 1.3 RPO.

Art. 1.4 RPO. Lo que se quiere evitar es que haya un laudo del TAH o informe de un grupo especial o del Órgano de Apelación del OSD que puedan ser eventualmente contradictorios. Ello quiere decir que la etapa diplomática del procedimiento de solución de controversias de la OMC, consistente en la celebración de consultas entre los Miembros de la OMC envueltos en la controversia no es impedimento para continuar las negociaciones de acuerdo a las normas del MERCOSUR. 


\section{1) Fase no judicial}

Cuando surge una controversia entre Estados miembros, estos deben realizar en primer lugar negociaciones directas las que deber ser conducidas por de los Coordinadores Nacionales del GMC de los Estados partes en la controversia o por los representantes que ellos designen ${ }^{29}$. De las negociaciones mismas y de los resultados alcanzados se debe notificar al $\mathrm{GMC}^{30}$. Si dentro de quince días desde que se notificó por una parte la existencia de la controversia no se alcanza ninguna solución o esta es solo parcial, puede solicitarse por cualquiera de los Estados involucrados que se inicie el procedimiento arbitral. Mientras estaba vigente el PB se prolongaba la etapa no judicial porque después de las negociaciones directas la controversia debía ser remitida al GMC antes de iniciar el procedimiento arbitral. Ahora dicha remisión es solo una posibilidad ${ }^{31}$.

\section{2) Fase arbitral}

\section{1) Constitución del Tribunal Arbitral Ad Hoc}

La intención de recurrir al procedimiento arbitral se debe comunicar a la Secretaría Administrativa del MERCOSUR (SAM) la que a su vez comunicará al otro u otros Estados involucrados en la controversia y al GMC a través de los coordinadores nacionales de este ${ }^{32}$. La SAM reúne

29

\section{Art. 14.2 RPO.}

30 Dicha comunicación se realiza a través de la Secretaría Administrativa del MERCOSUR (SAM). De acuerdo a la Decisión $n^{\circ} 30 / 02$ este órgano está autorizado para usar la denominación "Secretaría del MERCOSUR" solo para fines de divulgación.

Para eso deben acordarlo así los Estados involucrados en la controversia. También puede solicitar la intervención del GMC un Estado miembro que no sea parte de la controversia, pero para que se suspenda el procedimiento arbitral deben estar de acuerdo los Estados que sean parte de la controversia.

Cuando el GMC interviene por acuerdo de los Estados en disputa, aquel debe hacer recomendaciones que en lo posible sean expresas y detalladas para la solución del diferendo. Para ello se prevé que los Estados miembros presenten propuestas de solución de la controversia (Art, 17.1 RPO). Sin embargo, será difícil para el GMC hacer una recomendación, cuando no haya acuerdo entre los Estados en disputa, ya que el GMC está compuesto por representantes de cada Estado miembro, lo cual hace prácticamente inviable un acercamiento de las posiciones en disputa.

En el caso que la intervención del GMC no sea solicitada por un Estado que sea parte en la controversia, el GMC no está obligado a hacer comentarios o recomendaciones. Ya sea que los comentarios o recomendaciones deban o puedan hacerse pueden adquirir significado en la etapa arbitral.

En todos los casos la intervención del GMC no podrá exceder los treinta días. Véase PUCEIRO RIPOLL, Roberto, "El Protocolo de Olivos y el Régimen de Solución de Controversias del MERCOSUR" en Cuaderno de NEGOCIOS Internacionales e Integración Vol. VIII n. $36-40$ (2002), pp. 10-12. 
todas las informaciones acumuladas sobre la controversia y se encarga de todas las gestiones administrativas que le sean requeridas para el desarrollo de los procedimientos arbitrales ante el $\mathrm{TAH}^{33}$. Los miembros del TAH son designados dentro de quince días después desde que todas las partes en controversia han sido notificadas de la convocatoria del procedimiento arbitral ${ }^{34}$.

El TAH está compuesto de tres miembros que son designados para cada caso de dos tipos de listas que son confeccionadas por los Estados miembros ${ }^{35}$. Cada parte tiene derecho a nombrar un árbitro. El tercer árbitro o árbitro presidente, que no podrá ser nacional de ninguna de las partes en controversia, debe ser designado de común acuerdo entre las partes $^{36}$.

33 De acuerdo al Art. 18.2 RPO esas gestiones administrativas consisten en:

a. transmitir todas las comunicaciones de las partes al Tribunal Arbitral Ad Hoc y de este a las partes;

b. preparar un expediente con las actuaciones de la instancia arbitral y archivarlo

c. archivar la documentación relativa a los gastos de cada árbitro interviniente

d. prestar todo otro apoyo que le sea solicitado por el TAH y por las partes en la controversia.

El "importante apoyo administrativo para la labor del TAH" fue resaltado en el Laudo $\mathrm{N}^{\circ} 02 / 2006$ sobre impedimentos a la libre circulación en puentes entre Argentina y Uruguay de 6/9/2006, párrafo 83.

34 Art. 10.2 i) párrafo 1 y Art. 10.3 i) párrafo 1 PO.

35 Según el Art. 11.1 PO la primera lista está compuesta de cuarenta y ocho nombres, de los cuales cada Estado miembro nombra doce personas como posibles árbitros. Conforme al Art. 11.2 PO la segunda lista está compuesta de dieciséis nombres que son nombrados a razón de cuatro por cada Estado miembro, debiendo ser incluida al menos una persona como posible árbitro que no sea nacional del Estado proponente. De los integrantes de esta última lista se elige al tercer árbitro o árbitro presidente. El número total de personas que componen cada lista o la cantidad que le corresponde nombrar a cada Estado miembro deberá cambiar en conformidad a lo dispuesto en el Art. 1 párrafo segundo del Protocolo de Adhesión de la República Bolivariana de Venezuela al MERCOSUR. De la mencionada norma solo emana una obligación de adecuar la normativa del MERCOSUR a la incorporación del nuevo Estado miembro, pero no la forma concreta como se llevará a cabo esa adaptación normativa.

Se contempla asimismo en los Art. 11.1 i) PO y Art. 22 RPO un procedimiento para solicitar aclaraciones respecto de los nombres propuestos para la lista de cuarenta y ocho nombres de posibles árbitros. Los Art. 11.2 ii) PO y Art, 23 RPO establece adicionalmente la posibilidad de presentar objeciones respecto de las personas propuestas para la lista de árbitros presidente. Si no se halla a una solución entre el Estado proponente y objetante prevalece la objeción.

36 El Art. 10 PO establece además que si alguna de las partes deja de designar al árbitro a que tiene derecho, este será designado por la SAM dentro de dos días a partir del vencimiento del plazo general de quince días para hacer el nombramiento de árbitros. En el caso del árbitro que debe ser nombrado de mutuo acuerdo, si este no se alcanza, el árbitro es nombrado por la SAM previo sorteo del que se excluyen a los nacionales de los Estados partes en la controversia. En todos los casos se debe designar un árbitro suplente para el caso de incapacidad o excusa del titular. Por último, en el mismo artículo se prevé que la persona nombrada como tercer árbitro o árbitro presidente tiene tres días a contar de la notificación de su designación para aceptar su nombramiento. 


\section{2) Procedimiento y toma de decisiones del TAH}

El PO establece que los TAH deben sesionar en cualquier ciudad de un Estado miembro y que el TAH establece sus propias reglas de procedimiento, las que en todo caso deben atenerse al modelo aprobado por el $\mathrm{CMC}^{37}$. El procedimiento arbitral dura sesenta días, los que se cuentan desde la fecha en que el árbitro presidente ha aceptado su nombramiento. Este plazo se puede prorrogar en treinta días más. De esta prórroga se ha hecho uso en varias oportunidades ${ }^{38}$. Además se ha recurrido a la práctica de suspender los procedimientos, lo que en la práctica ha hecho extender la duración de los procedimientos arbitrales por sobre los plazos mencio$\operatorname{nados}^{39}$. La existencia de esta práctica debe haber servido de fundamento para que el PO después de caracterizar a los plazos antes indicados como perentorios agregue que estos pueden ser modificados de común acuerdo por las partes y siempre que el TAH lo autorice ${ }^{40}$.

El TAH adopta los laudos por mayoría de sus miembros. No se admiten votos de minoría y la votación para dictar el laudo así como las deliberaciones son confidenciales. La ausencia de votos disidentes es una regla que puede favorecer la autoridad de los laudos de los tribunales internacionales del MERCOSUR y que también es aplicada por el Tribunal de Justicia de las Comunidades Europeas (TJCE). La ausencia de votos disidentes favorece la autoridad de los tribunales internacionales del MERCOSUR, ya que al momento de su pronunciamiento los laudos no aparecen cuestionados. Esto no es menor para tribunales que siguiendo la regla general de la jurisdicción internacional, no disponen de medios de fuerza para hacer cumplir sus decisiones ${ }^{41}$. Asimismo, la au-

37 Las reglas modelo de procedimiento para los Tribunales Arbitrales Ad Hoc fueron aprobadas mediante la Decisión $\mathrm{n}^{\circ}$ 30/04.

38 C fr. I Laudo Arbitral de 28/4/1999, párrafo 4; III Laudo Arbitral de 10/3/2000 sección I.A.; IV Laudo Arbitral de 21/5/2001, párrafo I-A 5); V Laudo Arbitral de 29/9/2001 párrafos 1, 3 y 6; VI Laudo Arbitral de 9/1/2002 sección I. A.; VII Laudo Arbitral de 19/ 4/2002, párrafo 3.9; VIII Laudo Arbitral de 21/5/2002 sección "Constitución del Tribunal Arbitral" punto 6 y IX Laudo Arbitral de 4/4/2003 párrafo 8.

39 La suspensión del procedimiento ha sido solicitada por las partes y autorizada por el TAH (II Laudo Arbitral de 27/9/1999 párrafos 9, 10, 11 y IX Laudo Arbitral de 474/2003 párrafo 9), ha sido solicitada por el TAH y concedida por las partes (VI Laudo Arbitral de 9/1/2002 sección I. A.). También ha sido solicitada por una parte, consentida por la otra parte y aprobada por el TAH (X Laudo Arbitral de 25/8/2005 bajo el título "Antecedentes de la Controversia" párrafo 7) así como aprobada de oficio por el TAH (IX Laudo Arbitral, antes mencionado, párrafo 10). En el Laudo $\mathrm{n}^{\circ}$ 2/2006 del TAH de 6/9/2006, párrafo 13, consta que también fue solicitada la suspensión por una parte, pero esta fue rechazada, debido a que en el momento de la decisión el motivo de la solicitud ya no existía.

40 Art. 48.2 PO. Lo mismo se puede solicitar cuando el procedimiento se está llevando ante el TPR.

41 Helfer, Laurence R./Slaughter, Anne-Marie, "Toward a Theory of effective Supranational Adjudication" en Yale Law Journal, Tomo $107 \mathrm{~N}^{\circ} 2$ (1997), pp. 285-286. 
sencia de votos disidentes permite aislar a los jueces árbitros de las presiones de sus gobiernos ${ }^{42}$, cuestión que por cierto se debe evitar respecto de todos los jueces, pero que cobró actualidad en uno de los procedimientos arbitrales que se han seguido hasta ahora en el MERCOSUR, al ser criticada en uno de los Estados partes la actuación del juez árbitro de la misma nacionalidad ${ }^{43}$.

El Derecho aplicable en los laudos arbitrales son las fuentes normativas del MERCOSUR, a saber, el Tratado de Asunción y los demás instrumentos o tratados que lo complementan, los tratados celebrados entre los Estados miembros en el marco del MERCOSUR y las normas jurídicas aprobadas por los órganos decisorios de esta organización internacional así como los principios y disposiciones de Derecho Internacional Público aplicables a la materia. Igualmente las partes pueden acordar que el TAH decida ex aequo et bono ${ }^{44}$.

La jurisdicción del TAH es obligatoria, esto es, los Estados miembros del MERCOSUR están sometidos sin excepción a la jurisdicción del TAH sin que sea necesaria la aceptación de esta antes de iniciarse el procedimiento arbitral ${ }^{45}$.

Basados en la experiencia acumulada ${ }^{46}$ el PO y su reglamento establecen en forma más detallada cómo se fija el objeto de la controversia, esto es la cuestión respecto de la cual se deberá pronunciar el TAH. Así se ha establecido que el objeto de la controversia son los hechos, actos, omisiones o medidas cuestionados por ser incompatibles con la normativa MERCOSUR que quedan determinados por los escritos de demanda y de contestación de esta que se presentan ante el TAH, no pudiendo ampliarse con posterioridad. Además dichos escritos deben fundarse exclusivamente en aquellos asuntos que fueron tratados en la etapa no judicial del procedimiento de solución de controversias ${ }^{47}$.

\section{3) El surgimiento de una jurisprudencia arbitral}

El cambio en la composición de los miembros del TAH puede ser explicado en parte porque sus laudos arbitrales solo tienen efecto inter pares y no constituyen precedentes vinculantes para otros casos, ya que no

Helfer / Slaughter (n. 41), pp. 326-327 (incluida nota a pie de pág. n, 233).

En ese caso el árbitro cuestionado había votado en contra de la posición oficial de su país en la controversia y fue severamente criticado por el gremio empresarial. Ello demuestra la independencia del árbitro, pero permite augurar que la autoridad del TAH podría ser cuestionada más si se permitiesen votos disidentes. Véase TACCONE/ NOGUEIRA, Informe MERCOSUR $N^{\circ}$ 6, pp. 46-47.

WEHNER (n. 8), p. 103.

Ibídem.

Véase infra 2.3.1).

Art. 14 PO. 
se le podría atribuir a los árbitros de un TAH más autoridad que a otros. Sin embargo, la ausencia de obligatoriedad erga omnes la encontramos en tribunales internacionales permanentes como por ejemplo ocurre con la Corte Internacional de Justicia $(\mathrm{CIJ})^{48}$ o con las jurisdicciones nacionales de los países que no pertenecen al medio jurídico anglosajón. Ello no ha impedido que las sentencias o decisiones de esos tribunales se refieran a sentencias anteriores que han resuelto las mismas cuestiones jurídicas ${ }^{49}$. Lo mismos vale para los laudos arbitrales del TAH, los cuales expresa o tácitamente se han referido a las determinaciones de anteriores laudos. Por ello se puede hablar de una jurisprudencia arbitral ${ }^{50}$ del MERCOSUR en materias tales como el momento en que se determina el objeto de la controversia en los procedimientos de solución de controversias, el tratamiento de los obstáculos no tarifarios al comercio e interpretación restrictiva de las excepciones del Art. 50 del Tratado del Asociación Latinoamericana de Integración (ALADI), la aplicación de los principios de buena fe y de proporcionalidad en relación tanto al cumplimiento de las obligaciones de los Estados miembros que surgen de las normas del MERCOSUR como a la utilización de medidas o procedimientos que tienen un efecto restrictivo sobre la circulación de mercancías así como la determinación de las obligaciones de los Estados miembros una vez que ha sido aprobada una norma del MERCOSUR y respecto de la participación en el procedimiento arbitral de Estados que no son parte en la controversia.

\subsection{1) Determinación del Objeto de la Controversia}

Respecto a la determinación del objeto de la controversia se puede considerar que la jurisprudencia de los laudos arbitrales fue resolviendo esta cuestión con antelación a las normas posteriores y más precisas del $\mathrm{PO}^{51}$, por lo que probablemente ha inspirado a estas últimas. En al menos cuatro laudos arbitrales se reiteraron las normas del Reglamento del Protocolo de Brasilia (RPB) ${ }^{52}$ y se anticiparon las que posteriormente

\footnotetext{
48 Art. 59 Estatuto CIJ.

49 Seidl-Hohenveldern, Ignaz /Stein, Torsten, Völkerrecht (Heymanns, Colonia, Berlín. Bonn, Munich, 2000), p. 111 (n. al margen 519) y Verdross, Alfred/ Simma, Bruno, Universelles Völkerrecht - Theorie und Praxis (Duncker und Humboldt, Berlin, 1984) pp. 315-316 (n. al margen 618).

SARTORI, Marta Susana, "Laudo del Tribunal Ad Hoc del Mercosur en la controversia sobre subsidios a la producción y exportación de carne de cerdo" en Rey Caro, Ernesto/ Drnas de Clément, Zlata (eds.), Doctrina Jurisprudencial de los Laudos Arbitrales del MERCOSUR (Instituto de Derecho Internacional y Derecho de la Integración, Córdoba, 2004) p. 31.

51 En concreto se trata del Art. 14 PO,

52 Art. 28 RPB.
} 
contemplaría de manera más precisa el $\mathrm{PO}^{53}$ sobre la imposibilidad de ampliar el objeto de la controversia después de presentados los escritos de reclamación y su contestación. Adelantándose a las normas del PO, el TAH fue determinado en dichos laudos que el contenido de las reclamaciones durante la etapa no judicial es obligatorio, de tal modo que los escritos presentados al comenzar la etapa arbitral no pueden desvincularse de las alegaciones hechas durante la etapa anterior ${ }^{54}$. Que el PO haya recogido esa jurisprudencia clara sobre la forma y el momento en que se determina el objeto de la controversia en los procedimientos de solución de controversias del MERCOSUR puede ser también una reacción a un laudo arbitral que interpretó las normas aplicables de una manera divergente, negándole un carácter obligatorio al contenido de las alegaciones durante la etapa no judicial ${ }^{55}$. Adicionalmente, el TAH ha señalado que el cambio de denominación de la controversia entre la etapa diplomática y arbitral no constituye una modificación del objeto de la controversia, en tanto se esté haciendo referencia a los mismo hechos ${ }^{56}$.

\subsection{2) Obstáculos No Tarifarios al Comercio}

Dado que en el MERCOSUR hasta la fecha no se ha acordado un mecanismo automático para suprimir los obstáculos no tarifarios al comercio, la cuestión sobre la admisibilidad de los estos ha sido resuelta a través de laudos del TAH y del TPR. El aporte de la jurisprudencia arbitral del MERCOSUR es evidentemente solo parcial, en tanto los laudos carecen de obligatoriedad general, pero lo cierto es que el tratamiento de esta cuestión se ha repetido de manera constante. La jurisprudencia sucesiva del TAH ha reiterado básicamente la interpretación

Art. 14.1 PO. También ver supra 2.2).

I Laudo Arbitral de 28/4/1999 párrafo 54, II Laudo Arbitral de 27/9/1999 párrafos 4445, IV Laudo arbitral de 21/5/2001 párrafos 107-108 y VI Laudo Arbitral de 9/1/2002 n. II A. Además el X Laudo Arbitral de 5/8/2005 reitera esa jurisprudencia, sin perjuicio que fue dictado cuando ya regía el PO. Como la materia sobre la que se pronunció el $10^{\circ}$ TAH se refería a una controversia cuya tramitación se había iniciado bajo la vigencia del $\mathrm{PB}$, se aplicaron las reglas de este último y su reglamento. Cfr. X Laudo Arbitral de 5/ 8/2005 título "Objeto de la controversia" (pp. 8-13 de la versión encontrada el 12/10/ 2006 en el portal en Internet del MERCOSUR http://200.40.51.219/msweb/SM/es/Controversias/X\%20LAUDO.pdf).

55 III Laudo Arbitral de 10/3/2000 n. III B así como el laudo aclaratorio del mismo de $7 / 4 / 2000$ párrafo 1. También véase BaARs (n. 20), p. 311.

56 En la controversia sobre el cierre por grupos de personas durante el 2005 y el 2006 de puentes internacionales que comunican a Argentina y Uruguay resuelta a través del Laudo $\mathrm{n}^{\circ} 2 / 2006$ de 6/9/2006, Uruguay, que era el Estado reclamante, denominó durante la etapa de negociaciones directas como "impedimentos a la libre circulación derivados de los cortes", mientras que al iniciarse el procedimiento arbitral la denominó "omisión del Estado argentino en adoptar medidas apropiadas para prevenir y/o hacer cesar los impedimentos a la libre circulación". C fr. el párrafo 74 del laudo antes indicado. 
hecha en el Primer Laudo Arbitral ${ }^{57}$ que señaló que había un paralelismo entre la eliminación de los obstáculos arancelarios y la de los obstáculos no arancelarios, lo cual se desprende del $\mathrm{TA}^{58}$ y el Programa de Liberalización Comercial (PLC) ${ }^{59}$ que formaba parte de aquel como anexo I. De acuerdo a ese primer laudo arbitral, la circunstancia de que no hubiese un programa específico para la eliminación de los obstáculos no arancelarios al comercio no significaba que ellos no debían ser suprimidos, ya que por una parte, la supresión de esta clase de barreras comerciales es una meta establecida en el TA, y por otro lado, no es concebible una verdadera liberalización del comercio sin la supresión de ellas. Cumplido el plazo ${ }^{60}$ en el que debía existir un comercio intrabloque sin obstáculos, las únicas barreras no arancelarias al comercio autorizadas de acuerdo a las normas del MERCOSUR son aquellas que están destinadas a proteger los bienes jurídicos mencionados en el Art. 50 del Tratado de la ALADI ${ }^{61}$. Aparte de esta restricción de fondo para las medidas restrictivas no arancelarias, se impuso la obligación de armonizar las medidas nacionales restrictivas del comercio que estén destinadas a la protección de los bienes jurídicos indicados en el Tratado de la ALADI ${ }^{62}$.

57. I Laudo Arbitral de 28/4/1999 párrafos 64-71 y 72-79.

58 El Art. 1 párrafo 2 TA al comienzo señala que el Mercado Común implica: "La libre circulación de bienes, servicios y factores productivos entre los países, a través, entre otros, de la eliminación de los derechos aduaneros y restricciones no arancelarias a la circulación de mercaderías $y$ de cualquier otra medida equivalente (...)".

59 El Art. 1 párrafo 1 PLC decía: "Los Estados Partes acuerdan eliminar a más tardar el 31 de diciembre de 1994 los gravámenes y demás restricciones aplicadas en su comercio recíproco" y el Art. 10 párrafo 2 PLC expresaba: "Al 31 de diciembre de 1994 y en el ámbito del Mercado Común, quedarán eliminadas todas las restricciones no arancelarias". Sin perjuicio de lo anterior, no se establecía un mecanismo para la eliminación de las barreras no arancelarias. En el PLC el 1 de enero de 1995 era la fecha para el establecimiento de un comercio intrabloque libre de barreras de todo tipo. Para el TAH la fecha mencionada habría sido aplazada hasta el 1 de enero de 2000, cuando de acuerdo al Régimen de Adecuación Final hacia la Unión Aduanera, aprobado con posterioridad a la entrada en vigencia del TA, quedaban sin vigencia las restantes medidas restrictivas del comercio.

61 El Art. 2 letra b) PLC excluye expresamente a las "...medidas adoptadas en virtud de las situaciones previstas en el Artículo 50 del Tratado de Montevideo 1980". Este último dice: "Ninguna disposición del presente Tratado será interpretada como impedimento para la adopción y el cumplimiento de medidas destinadas a la: a) Protección de la moralidad pública; b) Aplicación de leyes y reglamentos de seguridad; c) Regulación de las importaciones o exportaciones de armas, municiones y otros materiales de guerra y, en circunstancias excepcionales, de todos los demás artículos militares; d) Protección de la vida y salud de las personas, los animales y los vegetales; e) Importación y exportación de oro y plata metálicos; $f$ P Protección del patrimonio nacional de valor artístico, histórico o arqueológico; y g) Exportación, utilización y consumo de materiales nucleares, productos radiactivos o cualquier otro material utilizable en el desarrollo o aprovechamiento de la energía nuclear".

62 I Laudo Arbitral de 28/4/1999 párrafos 80-81. También véase SAmtLeBeN, Jürgen, "Erster Schiedsspruch im Mercosur - wirtschaftliche Krise als rechtliche Herausforderung?" en Europäische Zeitschrift fiur Wirtschaftsrecht, Nr. 3 (2000), pp. 79-80. 
La interpretación antes indicada del $1^{\text {er }}$ Laudo Arbitral sobre la aplicación de barreras no arancelarias al comercio en el MERCOSUR ha sido reiterada por laudos arbitrales posteriores del $\mathrm{TAH}^{63}$. El $7^{\circ}$ Laudo Arbitral confirmó la misma línea interpretativa, agregando que las medidas restrictivas del comercio para la protección de los bienes jurídicos del Art. 50 del Tratado de la ALADI constituyen excepciones al libre comercio, que como tales deben ser interpretadas de manera específica y restrictiva, recayendo en el Estado que adopta la medida restrictiva no arancelaria la obligación de probar que se está protegiendo efectivamente algunos de las situaciones contempladas en el mencionado artículo del Tratado de la $\mathrm{ALADI}^{64}$. Esto último fue reafirmado por el Primer Laudo Arbitral del TPR que revocó el Undécimo Laudo Arbitral del TAH. Según el TPR, las medidas basadas en el Art. 50 del Tratado de la ALADI constituyen excepciones que siempre deben estar justificadas, que además no pueden ser aplicadas ni directa ni indirectamente de manera discriminatoria, sino que deben ser aplicadas de manera proporcional. Para el TPR la proporcionalidad de las medidas está directamente relacionada con el carácter de excepción y la obligación de justificarlas ${ }^{65}$.

\subsection{3) Principios pacta sunt servanda y proporcionalidad}

En los laudos arbitrales del MERCOSUR podemos hallar una interpretación y aplicación reiterada de los principios pacta sunt servanda y de proporcionalidad. Por ejemplo el $7^{\circ}$ Laudo Arbitral confirma la extensión del principio pacta sunt servanda dada en el $1^{\text {er }}$ Laudo Arbitral. Conforme a ellos se entiende que este principio implica el cumplimiento de buena fe de las normas del MERCOSUR por parte de los órganos de los Estados miembros, especialmente de aquellas normas que protegen la libre circulación de los factores productivos en un espacio económico que pretende integrarse. De acuerdo a ello no es suficiente solo la honestidad de los actos de ejecución y el apego formal a la letra de las normas del bloque, sino que se requiere que la actividad de los órganos estatales sea idónea para dar cumplimiento a los fines y objetivos de la normativa del MERCOSUR $^{66}$. Dicha idoneidad para establecer si el accionar o la omisión de cualquier órgano de un Estado miembro es o no compatible con las normas del MERCOSUR se mide además por el resultado de las

63 Cfr. III Laudo Arbitral de 10/3/2000 letra D.1, IV Laudo Arbitral de 21/5/2001 n. IIE-1 y VI Laudo Arbitral de 9/1/2001 letra B 1) c.

64 VII Laudo Arbitral de 19/4/2002 n. 9. Véase TACCONE/ NogueIrA: "Informe $\mathrm{N}^{\circ} 8$ (n. 7), pp. 82-82.

65 I Laudo Arbitral TPR n. 9-17.

66 VII Laudo Arbitral de 19/4/2002 párrafo 8.12 al invocar el considerando 56 del I Laudo Arbitral de 28/4/1999. 
acciones u omisiones de los Estados, según se desprende del Laudo $\mathrm{n}^{\circ} 2 /$ $2006^{67}$. El principio pacta sunt servanda se ha aplicado también para constatar las obligaciones que se derivan para los Estados miembros una vez que se aprueba una norma del MERCOSUR ya sea por los Estados miembros directamente o a través de los órganos decisorios del MERCOSUR. Dicha obligaciones son una de hacer y otra de abstención. La primera consiste en la incorporación al Derecho interno de las normas del MERCOSUR aprobadas. La segunda obligación consiste en no frustrar el fin de la norma aprobada, aunque aún no haya sido incorporada al Derecho interno ${ }^{68}$.

El $7^{\circ}$ Laudo se refiere también al principio de proporcionalidad establecido en el laudo inmediatamente anterior ${ }^{69}$. De acuerdo a este principio las restricciones al comercio pierden validez cuando la protección del bien jurídico de que se trate pueda ser alcanzada por medios menos restrictivos ${ }^{70}$. Esta interpretación fue confirmada por el primer laudo del TPR, aunque como el último criterio que debe analizarse para determinar la eventual legitimidad de una restricción al libre comercio ${ }^{71}$.

\subsection{4) Participación de Estados miembros que no son parte de la controversia}

Otra cuestión tratada por los laudos de los tribunales del MERCOSUR ha sido la facultad de que los Estados miembros que no son parte de la controversia puedan ser oídos por los órganos jurisdiccionales del MERCOSUR al momento de conocer de una controversia. Dicha facultad no está contemplada ni en el PO ni en el RPO, sin perjuicio que ya con anterioridad al primer pronunciamiento del TAH sobre esta materia se había considerado que dicha facultad fortalecería el efecto inter pares de los laudos arbitrales ${ }^{72}$. El $9^{\circ}$ TAH contempló por primera vez dentro de sus reglas de procedimiento, la facultad de participación de otros Estados miembros en la controversia bajo la condición que las partes de la controversia no se opusieren ${ }^{73}$. La misma facultad y sujeta a

67 Laudo $\mathrm{n}^{\circ}$ 2/2006 de 6/9/2006, párrafos 144-146 y 182-186.

68 Cfr. V Laudo Arbitral de 29/9/2001, párrafo 3.1, VII Laudo Arbitral de 19/4/2001, párrafos 7.7-7.8 y $8^{\circ}$ Laudo Arbitral de 21/5/2001 en la introducción de las consideraciones (párrafos 5 y 6) y en la consideración B. i).

VII Laudo Arbitral de 19/4/2002 párrafo 8.14.

VI Laudo Arbitral de 9/1/2002 sección II B. 1) c.

Los criterios que deben ser analizados en una medida restrictiva al comercio, antes de determinar si es compatible con la normativa del MERCOSUR hay que establecer: 1) si la medida es restrictiva del comercio, 2) si la medida es discriminatoria, 3) si la medida está justificada y 4) si es proporcional. Este último criterio estaría muy relacionado con el anterior. $C f r$. Laudo $\mathrm{n}^{\circ} 1 / 2006$ párrafos 14-17.

72 Alonso García (n. 16), p. 69.

73 Art. 13 párrafos 1 y 2 de las Reglas de Procedimiento del $9^{\circ} \mathrm{TAH}$. Que se contemplase esa posibilidad no debe extrañar, ya que el mismo autor de la nota a pie de página 
la misma condición fue prevista en las reglas de procedimiento del $10^{\circ} \mathrm{TAH}^{74}$.

Ha venido a ser el TPR, por medio de su primer laudo ${ }^{75}$, el que determinó que tenía la atribución y la responsabilidad institucional de dar traslado de oficio a los restantes Estados miembros del MERCOSUR para que entregasen sus puntos de vista en una controversia sin darle la calidad de partes. Ello se justificaba especialmente en aquellas controversias que tratasen sobre incumplimiento de las normas del MERCOSUR o incompatibilidad de las normas nacionales con aquellas ${ }^{76}$. Posteriormente el TAH volvió a hacer depender la participación de terceros del consenso de los Estados miembros partes en la controversia ${ }^{77}$.

\section{RECLAMACIONES DE PERSONAS NATURALES Y JURÍDICAS}

El PO introdujo solo modificaciones pequeñas en el procedimiento de reclamaciones para privados establecido por el $\mathrm{PB}$, el cual se había basado en el mecanismo contemplado para las reclamaciones de personas en el Tratado de Libre Comercio entre Canadá y EUA ${ }^{78}$. Como veremos a continuación, se trata de un procedimiento que depende en gran medida en la voluntad del Estado ante el cual el particular plantea la queja.

\section{1) Inicio del procedimiento}

Las personas naturales así como las jurídicas pueden, de acuerdo al PO, formular reclamaciones cuando un Estado miembro aprueba o aplica medidas legales o administrativas de efecto restrictivo, discriminatorias o de competencia desleal, en violación de alguna de las fuentes normativas

anterior era el presidente del TAH. Los Estados miembros, partes en la controversia, se opusieron a la manifestación en el proceso de los puntos de vista sobre la controversia de otros Estados miembros por lo que finalmente dicha posibilidad no existió. Cfr. IX Laudo Arbitral de 4/4/2003, párrafo 7.

74 Aquí también se contemplaba la mencionada posibilidad en el Art. 13 de las reglas de procedimiento. Al igual que Ia vez anterior, como se opuso el Estado miembro reclamante, no se concretó la posibilidad de que otro Estado miembro no parte manifestase su opinión sobre la controversia. Cfr. X Laudo Arbitral de 5/8/2005, párrafos 14 y 15 de la sección "Antecedentes de la controversia". Laudo $\mathrm{n}^{\circ} 1 / 2006$ de 20/12/2005, párrafo 24. En esa controversia los restantes Estados miembros hasta esa fecha participaron como terceros.

76 Lo que en la práctica abarcaría a todas las controversias que se han ventilado antes los tribunales del MERCOSUR. El TPR estimó además que los Estados que participasen en la controversia y no fuesen partes en ella, tenían el mismo deber de confidencialidad que los Estados miembros que fuesen parte de la controversia. Laudo $n^{\circ} 2 / 2006$ de 6/9/2006, párrafos 14-15. Tampoco hubo en esa controversia participación de Estados miembros como terceros.

78 HALPERIN, Marcelo, "Los Particulares y el MERCOSUR: el Protocolo de Brasilia para Ia solución de controversias" en Integración Latinoamericana, Vol. 17 No 178 (1992), p. 61. 
del MERCOSUR ${ }^{79}$. Para hacer la reclamación las personas naturales o jurídicas tienen que presentarlas en la Sección Nacional del Grupo Mercado Común del Estado Parte donde tengan su residencia habitual o comercial. El reclamante debe presentar informaciones que permitan comprobar la verosimilitud de la infracción de la normativa del MERCOSUR así como la existencia o amenaza de un daño para el reclamante $^{80}$. De lo anterior se concluye que no se trata de procedimiento de control abstracto, esto es, no basta con la sola infracción jurídica, sino que el particular debe sufrir perjuicio o estar bajo una amenaza real de sufrirlo. Esto diferencia especialmente al procedimiento de reclamación para particulares del mecanismo para solucionar las controversias entre Estados y ha sido confirmado por el TAH, de manera que el daño existente o la amenaza real de este debe ser demostrada por el Estado miembro ante el cual se presentó la reclamación en la eventualidad que la controversia llegue hasta la etapa arbitral ${ }^{81}$. En cambio en el procedimiento para la solución de controversias entre Estados puede llevarse a cabo un control abstracto dado que hay un mayor rango de circunstancias que pueden ser impugnadas incluyendo cuestiones de interpretación de las fuentes normativas del MERCOSUR y posibles omisiones del Estado contra el cual se levanta la reclamación ${ }^{82}$.

El que haya un perjuicio o una amenaza de él es una condición a nuestro juicio adecuada para conceder protección jurídica a los particulares. En cambio merece más reparos que el procedimiento de reclamaciones para particulares deje el control de admisibilidad en manos de una instancia no completamente imparcial, de forma tal que se limita el rol de los privados solo a la iniciación del procedimiento, lo cual impide hablar de una legitimación activa de los particulares ${ }^{83}$. El resto del pro-

Art. 39 PO.

Art. 40 PO y Art. 46 RPO.

II Laudo Arbitral de 27/9/1999 párrafos 41-41 en relación con párrafo 94. Véase LEHMANN, Julia, "Neues von der Schiedsgerichtsbarkeit des Mercosur - ein Integrationsmotor à la Luxemburg?" en Europäische Zeitschrift für Wirtschaftsrecht, Vol. 12 Nr. 20 (2001), p. 623 y THEN DE LAMMERSKÖTTER, Rosario, "Kommentar zum 2. Schiedsspruch" en: BASEDOW/ SAMTLEBEN (n. 12), p. 269.

82 ALONSO García (n. 16), p. 80. Sin embargo, en el laudo que resolvió la controversia entre Argentina y Uruguay sobre bloqueos realizados por particulares de puentes que unen a estos dos países, se da a entender que también se requiere probar los daños en las controversias interestatales,ya que si no "la violación transgrediría el principio de que se requiere interés para impulsar las acciones". A dicha interpretación no se le debería atribuir un carácter general, ya que más bien parece que se buscó darle un fin práctico a las abundantes pruebas entregadas por el Uruguay para acreditar los perjuicios económicos causados por el bloqueo de los puentes. Véase. Laudo $n^{\circ} 2 / 2006$ de 6/9/2006, párrafo 166 y ABIAD, Pablo, "Papeleras: críticas a los cortes de ruta en el fallo del Mercosur" en Clarin.com (en línea) [fecha de consulta: 2 de noviembre de 2006]. Disponible en: http:/ /www.clarin.com/diario/2006/09/07/elpais/p-00301.htm

WEHNER (n. 8), p. 104. 
ceso, como a continuación se muestra, depende básicamente de la disposición del gobierno del Estado en el cual se ha presentado la reclamación. Eso no excluye que después de la aceptación por parte de la Sección Nacional correspondiente de la GMC de la reclamación de un particular, que este coopere con el gobierno correspondiente para que se siga adelante con su reclamación, sobre todo en lo que concierne la entrega de medios probatorios ${ }^{84}$. Sin embargo, un procedimiento con esas características es susceptible de lobby político u otro tipo de consideraciones que no necesariamente se concilian con el interés del particular. Por otro lado hay que tener en cuenta que cuando el Derecho Internacional reconoce derechos a las personas, la regla general es que estos se hagan valer ante tribunales nacionales, mientras que la invocación de instancias internacionales constituye una excepción ${ }^{85}$. Incluso en las Comunidades Europeas los privados no disponen de la posibilidad de accionar jurídicamente contra un Estado miembro de la UE por incumplimiento de los tratados. Al contrario, solo la Comisión Europea o un Estado de la UE están legitimados activamente para denunciar a otro estado por incumplimiento de los tratados ${ }^{86}$, sin perjuicio de la manera como el TJCE ha ido desarrollando por medio de su jurisprudencia las funciones del procedimiento prejudicial ${ }^{87}$. Por eso que considerando la falta de un órgano que como la Comisión Europea pueda iniciar un procedimiento por infracción de la normativa del MERCOSUR, resulta positivo que en el

PuCeiro Ripoll, Roberto, "El Protocolo de Olivos y el Régimen de Solución de Controversias del MERCOSUR" en Cuaderno de NEGOCIOS Internacionales e Integración Año VIII, $\mathrm{n}^{\circ}$ 36-40 (2002), p. 15. SEIDL-HOHENVELDER/ STEIN (n. 49), p, 178 (n. al margen 936-937).

Arts. 226 y 227 TCE.

Nos referimos a la transformación del procedimiento prejudicial en un instrumento indirecto para impugnar normas nacionales contrarias al Derecho de la CE. La vía contemplada en el TCE para llevar a cabo está impugnación de normas nacionales es la acción por incumplimiento de los tratados, cuyo ejercicio está vedado para las personas. Sin embargo, el TJCE a través de la vía prejudicial, ha ido adquiriendo indirectamente la posibilidad de revisar la compatibilidad de normas nacionales con el Derecho de la CE. Esto se ha hecho entregando a los tribunales nacionales, que solicitan sentencias prejudiciales, criterios para ver si la norma nacional es compatible con el Derecho de la CE y darle preeminencia a este último. El rol del TJCE en este sentido es indirecto, ya que la competencia para anular o hacer inaplicable Derecho nacional corresponde normalmente los tribunales nacionales. Véase ALTER, Karen J., "Who are the 'Masters of the Treaty'?: European Governments and the European Court of Justice" en Internacional Organization Vol. 52 n. 1 (1998), p. 127; DAUSES, Manfred A., Das Vorabentscheidungsverfabren nach Artikel 177 EG-Vertrag (Ed. Beck, Munich, 1995) pp. 29-30, 49; MANCINI, G. Federico, "The Making of a Constitution for Europe" en Common Market Law Review Vol. 26 n. 4 (1989), p. 604; STEIN, Eric, "Lawyers, Judges and The Making of a transnacional Constitution" en American Journal of Internacional Law Vol. 74 n. 1 (1981), pp. 4-5 y 11; StreiNZ, Rudolf, Europarechty (Ed. C.F. Müller, Heidelberg, 2001), pp. 83-84 (n. al margen 223a) Wolf-Niedermaier, Anita, Der Europäische Gerichtshof zwischen Recht. und Politik (Ed. Nomos, Baden-Baden, 1997), pp. 53, 63-64. 
MERCOSUR esté previsto un procedimiento de reclamación para particulares, que al menos puede ser iniciado por estos. Además, el mencionado procedimiento representa un progreso que reconoce el rol de los privados en una economía de mercado, en comparación con anteriores proyectos de integración económica en América Latina en los cuales los particulares no disponían de ningún tipo de posibilidad para iniciar reclamaciones $^{88}$. Por último, no parece haber obstáculos para que tribunales nacionales, vayan desarrollando criterios jurídicos objetivos sobre los criterios de admisibilidad de reclamaciones de privados por parte de las secciones nacionales del GMC. Estas son al fin y al cabo autoridades nacionales que tiene que sujetarse al imperio del Derecho y a las cuales se les puede fijar claros márgenes de apreciación ${ }^{89}$.

\section{2) Procedimiento una vez que la reclamación ha sido acogida a tramitación}

Con las modificaciones introducidas por el $\mathrm{PO}$ el procedimiento para resolver las reclamaciones presentadas por particulares puede llegar a tener hasta cinco etapas. De esta forma, una vez que ha sido presentada y admitida una reclamación de una persona natural o jurídica, la respectiva Sección Nacional del GMC debe entablar consultas con su similar del Estado miembro contra el cual el particular ha levantado la reclamación $^{90}$. Los representantes de los Estados tienen quince días, contados desde el momento que se notificó al Estado contra el cual se hace la reclamación, para iniciar consultas por esta causa, salvo que se acuerde otro plazo ${ }^{91}$. Si no se ha alcanzado una solución, la Sección Nacional del GMC del Estado donde se hubiese hecho la reclamación, deberá elevar el reclamo al $\mathrm{GMC}^{92}$. La obligación de pasar a la siguiente etapa es una innovación del PO, ya que de acuerdo al PB el inicio de esta etapa era facultativo. Sin embargo, el carácter imperativo del inicio de esta nueva etapa se ve debilitado por la posibilidad de que el plazo para hallar una solución mediante consultas pueda ser aumentado y de eso modo se pueda retardar la tramitación de la reclamación del particular ${ }^{93}$.

RAMOS, Dante Marcelo, "Protección jurídica para los particulares en el MERCOSUR" en Contribuciones $\mathrm{n}^{\circ} 1$ (1999), Pp. 82-83.

89 AlONSO GARCía (n. 16) pp. 82-83.

90 Art. 40.1 PO y Art. 47 RPO. Véase PeNA, Celina/ Rozemberg, Ricardo, Una aproximación al desarrollo del MERCOSUR: sus fortalezas y debilidades (BID-INTAL, Buenos Aires, 2005), p. 29.

91 Art. $41.1 \mathrm{PO}$.

92 Art. 41.2 PO y Art. 48 RPO.

93 Santalla Vargas, Elizabeth/ SEnneKamp, Andreas, "Streitschlichtung als Integrationsfaktor in der Europäischen Union und im MERCOSUR" en Recht der Internationalen Wirtschaft, $\mathrm{n}^{\circ} 4$ (2002), p. 267.
} 
El GMC puede rechazar la reclamación, con lo cual terminaría su tramitación o puede aceptarla, lo que implica la convocatoria de un grupo de expertos. La decisión es tomada sobre la base de las informaciones entregadas por el reclamante acerca de la verosimilitud de la infracción de la normativa del MERCOSUR así como la existencia o amenaza de un daño para el reclamante ${ }^{94}$.

A diferencia del $\mathrm{PB}^{95}$, el $\mathrm{PO}$ indica expresamente que la reclamación será rechazada, cuando así es decidido de manera consensual por los integrantes del GMC, los que a su vez son representantes de cada uno de los Estados miembros. Ello quiere decir que cuando no existe acuerdo unánime de todos los integrantes del GMC, la reclamación se tiene por aceptada.

Al ser convocado el grupo de expertos, que se compone de tres personas, sus miembros son elegidos en primer lugar por consenso de una nómina confeccionada para tal efecto. A falta de acuerdo, se eligen las personas que hayan obtenido más votación. En caso de empate, elige la SAM a través de un sorteo. Salvo acuerdo en contrario, al menos una de las personas elegidas no debe ser nacional del Estado contra el cual se reclama ${ }^{96}$. Ante los expertos designados hay una audiencia en la que el reclamante y los Estados involucrados son oídos en conjuntamente ${ }^{97}$. La actuación del grupo de expertos dura treinta días y debe terminar con un informe acerca de la procedencia de la reclamación ${ }^{98}$.

Si el dictamen fundado del grupo de expertos considera unánimemente la reclamación del particular contra el Estado miembro respectivo como procedente, cualquiera otro de los países miembros podrá requerirle al primero la adopción de medidas correctivas o la anulación de las medidas declaradas como improcedentes. Si ese requerimiento no fuese seguido por el Estado contra el cual prosperó la reclamación dentro de quince días contados desde que se le hubiese solicitado, el Estado que

94 Art. 42 párrafos 1 y 2 PO y Art. 49.1 RPO.

Art. 29.1 PB. Bajo la vigencia del PB, la exigencia del mencionado consenso negativo se hizo explícita recién en el RPO (Art. 26), sin perjuicio que la doctrina ya había interpretado que el rechazo requería de la unanimidad de los miembros del GMC. Por lo tanto, es evidente que la evolución de esa normativa y la forma como ha sido interpretada ha influido en la regulación de esta cuestión a través del PO. Véase PUCEIRo RIPOLL (n. 31), p. 14 y WEHNER (N, 8), pP. 106-107 incluído pie de pág. $\mathrm{n}^{\circ} 127$. Art. 43.1 PO y Art. 49.2 RPO.

97 El Art. 42.3 PO dice que "(...) el grupo de expertos dará oportunidad al particular reclamante $y$ a los Estados (...) de ser oídos y de presentar sus argumentos (...)", mientras que el Art. 52.2 RPO señala que "(...) el grupo de expertos podrá fijar una audiencia (...)". 
hizo el requerimiento podrá iniciar el procedimiento arbitral contemplado para la solución de controversias entre Estados ${ }^{99}$. La ausencia de un plazo para el cumplimiento del dictamen del grupo de expertos, esto es, el desconocimiento de un efecto vinculante al informe de los expertos, es la mayor diferencia de este con el laudo arbitral del TAH o del TPR ${ }^{100}$. El dictamen adquiere carácter obligatorio solo cuando un Estado miembro lo requiera.

Cuando el grupo de expertos considere la reclamación particular como injustificada, o no haya unanimidad en las conclusiones del dictamen, el GMC dará por concluido el procedimiento. Si no hay unanimidad entre los expertos, las distintas conclusiones deberán ser entregadas al GMC. En ambos casos podrá darse inicio al procedimiento de solución de controversias entre Estados partes solicitando la iniciación de negociaciones directas al Estado contra el cual se levantó la reclamación por una persona natural o jurídica ${ }^{101}$.

En caso de rechazo, se estima que el reclamante puede recurrir a la justicia nacional para demandar al Estado miembro contra el cual reclama, ya sea directamente ante los tribunales de ese país o por intermedio de un socio comercial del reclamante en el Estado miembro contra el que se reclama, hipótesis que no es extraña en las relaciones comerciales internacionales ${ }^{102}$.

De los once laudos del TAH dictados hasta la fecha y no revocados, consta en el texto de al menos dos de ellos, que fueron iniciados por reclamaciones de particulares. Solo en uno de ellos se dejó constancia del desarrollo del procedimiento de reclamación de particulares y cual fue el dictamen del grupo de expertos ${ }^{103}$.

100 WEHNER (n. 8), p. 106.

101 Art. 44. párrafos 1 ii) y iii) y 2.

102 AlONSO GARCí (n. 16), p. 84 y RAMOS (n. 88), p. 83. Este señala: "Imaginemos a modo de ejemplo un negocio de exportación: si el Estado que no cumple es el del exportador, este debería presentarse antes sus tribunales nacionales. Abora bien, si el Estado parte que no cumple es aquel al cual se está exportando, quien debería entonces presentarse ante sus tribunales nacionales es el socio comercial de dicho exportador (en definitiva el importador del país en cuestión), reclamando a su Estado por la conducta infractora. Es decir que, dado que el negocio típico en el espacio integrado involucra generalmente a actores de ambos lados de las fronteras, aquel que se encuentra en el Estado parte infractor, interesado legítimo y afectado por la infracción, puede intentar vía sus tribunales nacionales obligar a su Estado a cumplir la normativa MERCOSUR, favoreciendo así a todas las partes del negocio".

103 Cfr. II Laudo Arbitral de 27/9/1999, párrafos 31-36 así como X Laudo Arbitral de 5/9/ 2005, sección titulada "Antecedentes de la controversia", párrafo 1-6. 


\section{SOluCión de CONTROVERSiAS ANTE LA COMISIÓN DE COMERCiO DEL MERCOSUR}

\section{1) El procedimiento de reclamación ante la Comisión de Comercio del Mercosur}

Este procedimiento de solución de controversias fue introducido por el POP ${ }^{104}$. Este señala que la interposición de una reclamación contra un Estado miembro ante la CCM no se opone al inicio de un procedimiento de reclamación de acuerdo a las reglas antes explicadas del $\mathrm{PO}^{105}$. Sin perjuicio de ello, se ha entendido que ambos procedimientos no se pueden iniciar paralelamente ${ }^{106}$, lo cual ha sido confirmado por la práctica seguida hasta ahora, ya que no consta en ningún laudo arbitral de los dictados hasta ahora, que la fase no arbitral haya sido iniciada de manera paralela ante el GMC así como ante la CCM.

En el marco de este procedimiento tanto personas como los Estados miembros pueden plantear conflictos para su solución. Para la determinación del objeto de la reclamación hay que distinguir una vez más si quien interpone la reclamación es una persona natural o jurídica o un Estado miembro y debe recaer en el ámbito de competencias de la CCM. Esto quiere decir que si se trata de un Estado miembro la reclamación debe referirse a la interpretación, aplicación o incumplimiento de cualquier fuente normativa del MERCOSUR, mientras que si se trata de un privado, se debe tratar de una violación de las mismas fuentes jurídicas cometida a través de la sanción o aplicación de medidas por parte de un Estado miembro que tengan un efecto restrictivo, discriminatorio o constituyan competencia desleal. Además la materia regulada por las normas del MERCOSUR que son materia del litigio deben estar relacionadas con la aplicación de los instrumentos de política comercial común acordados por los Estados miembros para el funcionamiento de la unión aduanera o se deben relacionar con las políticas comerciales comunes relacionadas con el comercio intrabloque o con terceros países ${ }^{107}$.

El procedimiento es iniciado cuando la reclamación es presentada por la respectiva Sección Nacional a la $\mathrm{CCM}^{108}$. Las reclamaciones de particulares se presentan ante la sección nacional correspondiente para que la reclamación sea comunicada a la CCM. Para que los antecedentes sean elevados a dicho órgano, el reclamante privado deberá contar por lo

\footnotetext{
104 Art. 21 POP y Anexo al POP

105 Art. 21 parágrafo primero POP en relación con el Art. 55.3 PO.

106 Alonso Garcfa (n. 16) pp.77-78 (incluida la nota a pie de página n. 76)

107 WEHNER (n. 8) p. 107-108.

108 Art. 2 Anexo del POP
} 
tanto con el acuerdo de la respectiva Sección Nacional de la CCM. A los particulares no se les exige probar la violación de las normas del MERCOSUR en materia comercial ni la existencia de una amenaza de perjuicio o este propiamente tal, como ocurre en el procedimiento ordinario para cursar sus reclamaciones, sin embargo su participación se reduce en comparación al procedimiento general, porque no existe ante la CCM ninguna instancia como el grupo de expertos, delante de la cual las personas puede alegar directamente sus argumentos ${ }^{109}$.

Si la CCM no toma ninguna decisión por consenso sobre la queja, se remiten los antecedentes de la reclamación a un comité técnico, el que elabora un dictamen dentro de treinta días corridos ${ }^{110}$. Este dictamen, o las distintas opiniones de los expertos, en caso que no se haya podido elaborar un dictamen común, se vuelven a enviar a la CCM para que se pronuncie sobre la controversia ${ }^{111}$. Si los integrantes de la CCM no toman una decisión de común acuerdo, se envían al GMC las diferentes alternativas propuestas para la solución del asunto junto al dictamen del comité técnico o las opiniones de sus integrantes. El GMC debe decidir dentro de 30 días $^{112}$.

En caso que se alcance un acuerdo respecto de la procedencia de la reclamación ya sea ante la CCM o ante la GMC, el Estado miembro reclamado debe tomar las medidas ordenadas dentro del plazo que se haya fijado por uno de los dos órganos decisorios anteriores, plazo que deberá ser razonable ${ }^{113}$. Hay que tener presente que el Estado reclamado debería cumplir de manera diligente, considerando que a través de se representante ante la CCM habría concurrido a la decisión sobre la procedencia de la reclamación. En el caso que no se alcance un acuerdo sobre la procedencia o no de la reclamación o si esta se estima procedente, pero el Estado respectivo no cumpliese con lo ordenado, el Estado miembro reclamante, puede iniciar un procedimiento arbitral ${ }^{114}$.

El Primer ${ }^{115}$, Segundo ${ }^{116}$ y Octavo ${ }^{117}$ laudos arbitrales del MERCOSUR fueron dictados como consecuencia de una reclamación hecha ante la CCM.

111
Alonso Garcia (n. 16), p. 87.

Última oración del Art. 2 del Anexo del POP.

Art. 3 del Anexo del POP.

Art. 5 del Anexo del POP.

Art. 6 del Anexo del POP.

Art. 7 del Anexo del POP.

SAMtLEBEN "Schiedsspruch" (n. 62), p. 78. y I Laudo Arbitral de 28/4/1999 párrafos 19 y 46.

II Laudo Arbitral de 27/9/1999, párrafos 1-2 y 31-36.

VIII Laudo Arbitral de 21/5/2002. 


\section{2) El procedimiento de consulta ante la CCM}

Este procedimiento fue creado por la propia $\mathrm{CCM}^{118}$. En la práctica este procedimiento ha jugado una función de "válvula de escape" a través de la cual se resolvían regularmente controversias, lo cual trajo como consecuencia que por largo tiempo no se recurriese a los medios formales para resolver reclamaciones que se han explicado anteriormente ${ }^{119}$. Por ejemplo entre 1995 hasta mayo 1997 se tramitaron aproximadamente doscientas cincuenta consultas, de las cuales más de la mitad de ellas terminaron como "concluidas" 120 . La falta de utilización de los mecanismos formales de solución de controversias hasta finales de la década de 1990 ha sido considerada como una prueba de falta de funcionalidad del mecanismo formal contemplado para dicho fin ${ }^{121}$, lo cual podría reforzar el planteamiento que sostiene la preferencia de los Estados de América Latina por los mecanismos informales para solucionar sus controver$\operatorname{sias}^{122}$. Sin embargo, los diez laudos dictados hasta la fecha por el TAH, sin considerar el que ha sido revocado por el TPR ${ }^{123}$, más los dos laudos del órgano jurisdiccional permanente del MERCOSUR, podrían ser considerados como un cambio de tendencia por lo menos en lo que se refiere a los Estados miembros del MERCOSUR.

El procedimiento de consulta ante la CCM permite a un Estado miembro solicitar a otro un pronunciamiento sobre actos normativos específicos o prácticas llevadas a cabo en el último que sean consideradas por el Estado solicitante como incompatibles con las normas del MERCOSUR. El rol de la CCM sería más bien de intermediación ${ }^{124}$.

De acuerdo a la Directiva $\mathrm{n}^{\circ} 17 / 99$ las consultas tienen que referirse a materias que caen a la competencia de la CCM, que como ya se ha dicho son los instrumentos comerciales del MERCOSUR. La agilidad del procedimiento de consulta se busca a través de una notificación rápida y la unificación de las consultas que se refieran a una misma materia. El plazo

118 Ordenadas de manera cronológica el procedimiento de consulta ante la CCM ha sido regulado por las directivas $\mathrm{n}^{\circ} 13 / 95, \mathrm{n}^{\circ} 6 / 96 \mathrm{y} \mathrm{n}^{\circ} 17 / 99$.

119 SAMTLEBEN "Rechtssystem" (n. 12), p. 82 y "Schiedsspruch" (n. 62), p. 78.

120 NOOd TAquela, María Blanca, "Solución de Controversias en el Mercosur" en Jurisprudencia Argentina, Tomo III (1997), p. 877.

121 LEHMANN (n. 81), p. 622.

122 ORRego VicuÑA, Francisco, "Análisis de la práctica latinoamericana en materia de solución de controversias durante la década de 1970 y sus implicaciones para el futuro" en OrRego Vicuña, Francisco/ Irigoin Barrene, Jeannette (eds.), Perspectivas del derecho internacional contemporáneo y visión de América Latina Tomo II (Ed. Universitaria, Santiago de Chile, 1981) pp. 93-94.

123 El laudo de TAH de 25/10/2005 fue revocado por el laudo del TPR de 20/12/2005.

124 SAmtleben (n. 12), p. 82 haciendo referencia a INTAL, Carra Mensual Nr. 28 (November 1998). 
de contestación de ninguna manera puede exceder de 60 días. Además se prevén formularios para la consulta y su respuesta.

El procedimiento de consulta puede terminar de tres maneras. En primer lugar consta una consulta como "concluida" si la contestación satisface al Estado que planteó la consulta o la causa que la generó hubiese sido superada. En segundo lugar terminará un procedimiento de consulta como "concluido insatisfactoriamente" si el objeto de disputa no se resuelve o por causa de la misma cuestión consultada se recurre a los procedimientos de solución de controversias ya descritos. En el texto del VIII Laudo Arbitral consta que antes de ser iniciado el procedimiento formal para la solución de la controversia, primero se planteó una consulta en la $\mathrm{CCM}^{125}$. Por último, una consulta terminará como "concluida por expiración del plazo" cuando después de cuatro reuniones de la CCM todavía no haya sido resuelta, salvo que los Estados involucrados acuerden algo distinto.

El procedimiento de consulta fue concebido en realidad como un mecanismo para los Estados miembros, sin que las normas pertinentes regulasen que se planteen consultas por privados. Sin embargo, se presentaron durante la década de 1990 una gran cantidad de consultas basadas en problemas que afectaban a privados. En la práctica, no es que las consultas hayan sido planteadas directamente por particulares, sino que estas han sido planteadas a través de las respectivas secciones nacionales de la CCM, habiéndose hecho valer en forma de consultas problemas que afectaban el normal tráfico de mercancías, esto es, obstáculos arancelarios y no $\operatorname{arancelarios}^{126}$.

\section{APLICACIÓN DE LAS NORMAS DEL MERCOSUR POR LOS TRIBU- NALES NACIONALES}

Anteriormente ya se ha indicado ${ }^{127}$ que la regla general es que los derechos que resulten de normas de Derecho Internacional sean hechos valer ante tribunales nacionales. Lo anterior también vale para las fuentes normativas del MERCOSUR. Como ya fue explicado ${ }^{128}$, los particulares pueden hacer uso de un procedimiento de reclamaciones específico, cuando en un Estado miembro, distinto de aquel donde se tenga residencia habitual o comercial, se aprueban o aplican medidas legales o administrativas de efecto restrictivo, discriminatorias o de competencia desleal, en violación de alguna de las normas jurídicas aprobadas por los órganos

\footnotetext{
125 VIII Laudo Arbitral de 21/5/2002 en la parte "Inicio del procedimiento ante la CCM del MERCOSUR" párrafos 1-4.

126 NoOd TAquela (n. 120), pp. 877-879 y SAmtleben (n. 12), p. 82.

127 Supra IV. 1).

128 Supra IV.
} 
del MERCOSUR o en el marco de este. Este procedimiento, si bien es puesto en marcha por iniciativa particular, no contempla, como ya se ha visto, una verdadera legitimación activa de los privados, sino que es el Estado ante cuya Sección Nacional de GMC se presenta la reclamación particular el que lleva adelante el procedimiento. Por lo tanto, la regla general para los particulares es que estos están legitimados para invocar los derechos o beneficios establecidos en su favor por las normas aprobadas en el MERCOSUR ante los tribunales estatales, ya sea respecto de la Administración de un Estados miembro así como frente a particulares ${ }^{129}$. La vía internacional a través del procedimiento de reclamaciones será la única forma de impugnar la actuación de un Estado miembro violatoria de las normas del MERCOSUR, cuando el reclamante no cuente con un socio con residencia habitual o comercial en dicho Estado que también se vea afectado por el incumplimiento estatal de la normativa del bloque comercial ${ }^{130}$.

La constatación de derechos subjetivos reconocidos por las normas del MERCOSUR por parte de los tribunales nacionales es una consecuencia lógica del objetivo de este bloque sudamericano de constituir un mercado común. Uno de los elementos del concepto de mercado común establecido en el Tratado de Asunción es la libre circulación de bienes, servicios y factores productivos ${ }^{131}$, los que como tales no son los que se benefician de circular libremente, sino que las personas que ejercen el comercio o prestan servicios y tengan contrapartes en otro país del MERCOSUR o que quieran trabajar en otro Estado miembro. En otras palabras, la construcción de un mercado común supone la iniciativa privada y además que ella extienda su campo de acción en un mercado unificado que traspase las fronteras nacionales y está compuesto por todas las economías nacionales que conforman el bloque. La adopción de las normas entre los Estados miembros para la creación de un mercado común implica acordar reglas internacionales para armonizar la conducta de las administraciones nacionales, lo que desde el punto de vista del agente económico privado, no es otra cosa que la restricción de la discrecionalidad de que gozaban las administraciones nacionales antes de la formación de esa organización internacional. Por ello es lógico, que se atribuya a los beneficiarios de las normas que garantizan el mercado común la posibilidad de invocarlas frente a las administraciones, que no es otra

129 Alonso García (n. 16), p. 143; EkmeKdjian, Miguel Angel, "¿Una Constitución para el Mercosur?" en Anuario de Derecho Constitucional Latinoamericano (1999), p. 83, KLEINHEISTERKAMP, Jan, "Seguridad Jurídica en el MERCOSUR: La interpretación uniforme del derecho comunitario" en Revista de Derecho Privado y Comunitario (2000-1), pp. 546550, RAMOS (n. 88) p. 83 así como SAMTLeben "Rechtssystem" (n. 12), p. 81.

131 Art. 1 Tratado de Asunción 
cosa que decir que se le atribuya derechos subjetivos. Esto no pierde validez por el hecho de que las normas del MERCOSUR deban ser incorporadas en los ordenamientos jurídicos nacionales, a menos que se sostenga una doctrina de la transformación del Derecho Internacional en el Derecho nacional que se funde en un dualismo radical entre ambos tipos de ordenamientos jurídicos ${ }^{132}$.

La determinación sobre la aplicabilidad directa o la calidad de selfexecuting ${ }^{133}$ de las disposiciones de las normas del MERCOSUR, es decir, determinar si producen efectos en los ordenamientos jurídicos de los Estados miembros sin necesidad de medidas internas de complementación o concreción ${ }^{134}$ y sin perjuicio del acto de incorporación en los ordenamientos jurídicos nacionales del respectivo acto normativo de un órgano decisorio del MERCOSUR o del tratado acordado en su marco, es una cuestión de interpretación ${ }^{135}$. Lo mismo vale para determinar si de una disposición del MERCOSUR se derivan o no derechos subjetivos ${ }^{136}$. A este respecto no basta con interpretar la voluntad de los Estados parte del respectivo tratado o de sus respectivos representantes en los órganos del MERCOSUR, ya que de acuerdo a la Convención de Viena sobre el Derecho de los Tratados (CVDT) predominan los criterios objetivos de interpretación, lo cual también sería aplicable a la determinación de si una disposición es o no self-executing ${ }^{137}$.

La existencia de normas self-executing ha sido determinada ya en el primer laudo de un tribunal arbitral del MERCOSUR ${ }^{138}$ y confirmado de manera reiterada en sucesivos laudos con respecto a la circulación de

132 RUDOLF, Walter, "innerstaatliches Recht und Völkerrecht" en SEIDL-HOHENVELDERN, Ignaz (ed.), Lexikon des Rechtes/Völkerrecht, p. 315 y Verdross/SImma (n, 45), p. 545 (n. al margen 858)

133 VERDROSS/ SimMA (n. 49), p. 550 (n. al margen 864).

134 Vid. SeIdL-HOHENVELdern, Ignaz / LOIBL, Gerhard, Das Recht der Internationalen Organisationen einschließlich der Supranationalen Gemeinschaften (n. 49), p. 257 (n. al margen 1704); SEIDL-HOHENVELDERN /STEIN (n. 49), pp. 121-122 y MONTT OYARZún, Santiago, “Aplicación de los Tratados Bilaterales de Protección de Inversiones por Tribunales Chilenos. Responsabilidad del Estado y Expropiaciones Regulatorias en un Mundo Crecientemente Globalizado" en Revista Chilena de Derecho Vol. 32 n. 1 (2005), pp. 29-34; RUDOLF (n. 132), p. 316.

136 En concepto de VERDRoss/ Simma (n. 45), p. 551 (n. al margen 864) sería un caso de aplicabilidad directa en sentido estricto. Cfr. IRIGOIN BARRenNe, Jeannette, "La Convención Americana de Derechos Humanos como derecho interno chileno" en INFANTE CAFFI, María Teresa / CAVE SCHNÖHR, Rose, Solución judicial de controversias: el derecho internacional ante los tribunales internacionales e internos (Universidad de Chile, Santiago, 1995), Pp. 33-34.

137 BERnHARD, Rudolf, "Vertragsauslegung" en SEIDL-Hohenveldern, Ignaz (ed.), Lexikon des Rechts Völkerrecht (Ed. Luchterhand, Neuwied, Kriftel, 2001, 3" ed.), pp. $506-509$ y Verdross/ Simma (n. 49), pp. 553-554 (n. al margen 866).

138 I Laudo Arbitral de 28/4/1999 párrafo 64, SAMTLEBEN (n. 12), p. 63 y SARTORi (n. 50), p. 24 . 
mercancías libre de obstáculos ${ }^{139}$. Asimismo las normas del MERCOSUR, ya sea que estén establecidas en tratados o hayan sido adoptadas por alguno de sus órganos, han sido invocadas por privados o reparticiones públicas nacionales o por miembros de tribunales colegiados o aplicadas por tribunales de los Estados miembros en materias tales como certificados de origen, derecho a las exportaciones, internación de vehículos de turistas y diferentes aspectos de la cooperación judicial internacional ${ }^{140}$.

\section{ViI. El Tribunal Permanente de Revisión}

Como ya se ha indicado, la creación del TPR constituye la más importante innovación del PO y tiene por consecuencia que los laudos arbitrales del TAH no son más inapelables. Su creación corresponde por una parte al deseo de garantizar la unidad de la interpretación por medio de una autoridad más allá del litigio concreto $^{141}$, cuestión que se hace evidente en la posibilidad de solicitarle opiniones consultivas y por ende hacer interpretaciones desvinculadas de litigios concretos ${ }^{142}$. Por otra, el establecimiento del TPR está revestido de las reservas que los Estados tienen respecto de la jurisdicción internacional y especialmente respecto de la que tiene carácter permanente, dado que a diferencia de lo que ocurre con los medios diplomáticos de solución de controversias internacionales, los Estados tienen menos control sobre el resultado final expresado en una sentencia o laudo ${ }^{143}$. Además cuando se acuerda un método jurisdiccional para la solución de controversias, los Estados prefieren el arbitraje por sobre los tribunales permanentes, dado que el arbitraje es más flexible y le da más influencia a los Estados para determinar el

139 Cfr. III. Laudo Arbitral de 10/3/2000, sección III D. 1; IV Laudo Arbitral de 21/5/2001, sección II-E-I y VI Laudo Arbitral de 9/1/2002, sección II B b).

140 En detalle se analizan algunos casos donde han sido tratadas estas materias por tribunales nacionales en FUNDACIÓN KONRAD ADENAUER (FKA) / Secretaría del MERCOSUR (eds.), Primer Informe sobre la Aplicación del Derecho del MERCOSUR por los Tribunales Nacionales (2003) (FKA, Berlín, Montevideo, 2005), pp. 36-66 y 73-86 así como FKA/ Secretaría del MERCOSUR (eds.), Segundo Informe sobre la Aplicación del Derecho del MERCOSUR por los Tribunales Nacionales (2004) (FKA, Oficina Uruguay y Secretaría del MERCOSUR, Montevideo, 2006), pp. 43-79, 132-150, 170-196.

141 Decisiones $n^{\circ} 25 / 00$ y $n^{\circ} 65 / 00$. Véase CONSEJO ARgentino PARA LAS RElaciones INTERNACIONALES (CARI)/ FKA, Taller de Reflexión "Solución de Controversias en el Mercosur: Evaluación y Propuestas" Análisis de los tres primeros laudos (CARI/FKA, Buenos Aires, 2000), pp. 8-9 y DíAZ Pereira, Ramón, Protocolo de Olivos: algunas reflexiones sobre los institutos que deben ser abjeto de reglamentación específica en "Cuaderno de NEGOCIOS Internacionales e Integración" Vol. VIII n. 36-40 (2002), pp. 22-23.

142 Véase infra VII 3).

143 Véase MalanczuK, Peter, "Einvernehmliche Streitbeilegung" en Lexikon des Rechtes/ Völkerrecht (Ed. Luchterhand, Neuwied/ Kriftel, 2001, p.412; OeLlers-FraHM, Karin, "Probleme und Grenzen der obligatorischen internationalen Gerichtsbarkeit", en Archiv des Völkerrechts, Tomo 27 (1989), pp. 442-444. y ORREGO VICUÑA (n. 122), p. 96. 
asiento del tribunal, los límites de su competencia, su composición, procedimiento así como el Derecho aplicable ${ }^{144}$. Lo anterior se refleja en algunos elementos que debilitan la autoridad que se deriva del carácter permanente de la jurisdicción del TPR. Por ejemplo para que el TPR sea competente como única instancia se requiere el acuerdo expreso de los Estados envueltos en la controversia ${ }^{145}$, con lo cual se asimila a la jurisdicción internacional facultativa ${ }^{146}$, esto es que requiere convención especial entre las partes para el caso concreto, en oposición a la jurisdicción internacional obligatoria que se deriva por ejemplo de la adhesión a la cláusula facultativa del Estatuto de la $\mathrm{CIJ}^{147}$ o respecto del TAH en el MERCOSUR. Además los miembros del TPR no son denominados "jueces" sino que "jueces árbitros"148 y duran en sus cargos períodos de dos o tres años, lo cual es muy breve si se considera la necesaria estabilidad e independencia que requieren los jueces para el ejercicio de sus labores $^{149}$. Por último, las decisiones del TPR son denominadas "laudos" en vez de "sentencias"150.

\section{1) Composición del TPR}

El TPR está compuesto de cinco miembros ${ }^{151}$. Cada Estado miembros debe nombrar un árbitro y su suplente. En este caso el cargo dura dos años, pudiendo ser reelegidos por dos períodos consecutivos como máximo ${ }^{152}$. El quinto árbitro, que debe ser nacional de uno de los Estados miembros, es elegido de común acuerdo por ellos de una lista que contiene ocho nombres

\footnotetext{
144 Malanczuk, Peter (n. 143), p. 411 y Samtleben: "Rechtssystem" (n, 12), p. 85.

145 Art. 23.1 PO y Art. 39.1 RPO

146 MalanczuK, Peter (n. 143), p. 411.

147 Art. 36 Estatuto CIJ.

148 Art. 18.1 PO y Art. 31 RPO.
}

149 La relación entre independencia de los jueces y duración de los cargos fue abordada hace unos poco años con motivo de la reforma a la judicatura de la UE que fue llevada a cabo por el Tratado de Niza que entró en vigor el 1 de febrero de 2003. El llamado Grupo de Reflexión compuesto en su mayoría por ex jueces del Tribunal de Justicia de la UE (TJUE) y dirigido por su ex presidente Ole Due propuso duplicar la duración en el cargo de los jueces del TJUE a doce años, equiparándolo al que gozan los magistrados del Tribunal Constitucional alemán. Véase Olivares Tramón, José Miguel/ Tüllmann, Norbert "Die künftige Gestaltung der EU-Gerichtsbarkeit nach dem Vertrag von Nizza" en Neue Zeitschrift für Verwaltungsrecht, Nr. 1 (2004), p. 48. También se ha propuesto una prologación de la duración de los cargos de los integrantes del Órgano de Apelación del Órgano de Solución de Diferencias de la OMC por las mismas razones hechas valer respecto de la jurisdicción de la UE. Véase HILF, Meinhard/ OETER, Stefan, WTO-Recht Rechtsordnung des Welthandels (Ed. Nomos, Bade-Baden, 2005), p. 519 (n. al margen 36).

iso Art. 21 PO y Art. 38 RPO.

151 Art. 18.1 PO. Las cifras de los miembros del TPR y de la lista para elegir el quinto árbitro debiesen cambiar según lo dispuesto en el Protocolo de Adhesión de la República Bolivariana de Venezuela. Véase suprá pie de pág. n. 35. 
de posibles árbitros, de los cuales dos personas son designadas por cada Estado miembro. Si no hay acuerdo para elegir al quinto árbitro, este debe ser elegido por la SAM por sorteo de entre los nombres de la lista indicada. El período del cargo dura tres años, sin posibilidad de reelección, a menos que los Estados miembros acuerden otra $\operatorname{cosa}^{153}$. Por último, el PO señala expresamente que los Estados miembros pueden acordar otros criterios para designar el quinto árbitro ${ }^{154}$.

\section{2) Competencia del TPR}

De lo visto hasta ahora se desprende que el TPR puede actuar tanto como un tribunal revisor de cuestiones de Derecho ${ }^{155}$ o como tribunal de única instancia. En ambos casos el TPR las mismas fuentes del Derecho que el TAH, a menos que como tribunal de única instancia se le haya concedido por las partes la facultad de decidir de acuerdo a principios de equidad (ex aequo et bono $)^{156}$. En el primer caso, el recurso de revisión de que conoce el TPR debe ser interpuesto ante él dentro de quinces días contados desde la notificación del laudo arbitral del TAH ${ }^{157}$. A través de este recurso el TPR solo puede pronunciarse sobre cuestiones de Derechos tratadas ante el TAH, excluyéndose la revisión de los laudos que se hayan dictado conforme a principios equidad ${ }^{158}$. Respecto de lo que se entiende por cuestiones de Derecho, el TPR tuvo oportunidad de pronunciarse en su primer laudo arbitral. Allí se estableció que al TPR no solo le correspondía velar por la correcta interpretación del Derecho en su sentido objetivo, sino que, tal como ha sido la evolución histórica de la función del recurso de casación, también por la legalidad del procedimiento así como los derechos de las partes. En este último rol tutelar, la competencia del TPR en base al recurso de revisión también abarcaría garantizar una correcta valoración de la prueba. Asimismo, el TPR considera que en su competencia revisora no le impide referirse a los hechos cuando sea necesario para realizar interpretaciones jurídicas adecuadas ${ }^{159}$.

Presentado el recurso, la otra parte dispone de quince días para replicar los argumentos del recurrente. El TPR tiene treinta días para decidir contados desde a contestación de la otra parte o una vez que haya transcurrido el plazo para hacerlo sin que lo haya realizado. El plazo para

\footnotetext{
153 Art. 18.3 PO así como Art. 31 párrafos 4 y 5 RPO.

154 Art. $18.4 \mathrm{PO}$.

15s Art. $17.2 \mathrm{PO}$.

156 Art. 34 PO.

157 Art. 17.1 PO.

158 Art. 17 párrafos 2 y 3 PO.

159 Laudo $\mathrm{n}^{\circ} 1 / 2006$ de 20/12/2005, párrafos $1-4$ y su respectivo laudo aclaratorio de $13 / 1$ / 2006, párrafo VI.
} 
decidir puede prolongarse eventualmente en quince días más ${ }^{160}$. A través del laudo el TPR puede confirmar revocar parcial o completamente el laudo del TAH. Dicha decisión no se puede recurrir ${ }^{161}$. Conforme a ello el TPR ha rechazado el recurso de revisión de actuaciones del TAH distintas al laudo ${ }^{162}$.

Para que el TPR actúe como tribunal de única instancia debe cumplirse previamente la etapa no judicial. Iniciada la etapa judicial, el TPR tiene las mismas facultades que el TAH. En este caso, el laudo será inapelable ${ }^{163}$.

\section{3) El Procedimiento de Consulta}

A parte de las competencias mencionadas del TPR para solucionar diferencias, el órgano jurisdiccional permanente se puede pronunciar emitiendo opiniones consultivas. Esta atribución quedó sin ser regulada en detalle por el PO, por lo que nada se estableció sobre los efectos de esos dictámenes ni sobre quienes estaban facultados para solicitarlas. El PO delegó la regulación de esta competencia del TPR en el CMC, el que lo hizo parcialmente mediante la aprobación del RPO. De acuerdo a él, las opiniones consultivas pueden ser solicitadas por los Estados miembros en conjunto, los órganos decisorios del MERCOSUR así como los tribunales superiores de los Estados miembros con jurisdicción nacional. Sin embargo, en el último caso el detalle de la reglamentación del procedimiento está aún pendiente, ya que para ello se requiere adicionalmente que los tribunales nacionales superiores de cada Estado sean consultados. Cuando la solicitud es hecha por los Estados miembros en conjunto, una vez que el contenido y objetivo de la opinión consultiva haya sido acor-

162 Laudo $\mathrm{n}^{\circ}$ 2/2006 de 6/7/2006, Sección III, párrafos 2-4. Se trató del segundo laudo del TPR y por medio de él fue rechazada la pretensión de la parte solicitante de revisar la decisión del TAH que conocía de la controversia sobre su propia composición. El TPR declaró que dicha resolución del TAH no constituía un laudo, siendo este último un requisito establecido expresamente en el Art. 17.1 PO. Otro argumento dado por el TPR dice relación con el interés privado en solucionar más ágilmente una controversia, lo cual sería una de las justificaciones del arbitraje. Sin embargo, a nuestro juicio dicho argumento no guarda relación con el arbitraje internacional obligatorio. En este caso no estamos frente a medio alternativo de solución de controversias, sino el único medio contemplado. Junto a la solución rápida de las controversias debe considerarse que la obediencia a la jurisdicción internacional descansa mucho en el rigor argumentativo.

El recurso de revisión antes mencionado había sido interpuesto por Argentina. Este país había recusado al integrante español del TPR por tener la misma nacionalidad de una de las papeleras que se construyen en la orilla uruguaya del Río Uruguay. Dicha recusación había sido rechazada por el TPR, lo que llevó a la interposición del recurso de revisión. Véase ABIAD (n. 82). 
dado, el Estado miembro que ostente la presidencia pro tempore del MERCOSUR debe redactar el texto de la opinión consultiva y presentarlo ante la Secretaría del TPR. Esta también recibirá la solicitud de interpretación cuando el peticionario sea un órgano decisorio. El texto de la solicitud de opinión consultiva debe contener claramente la cuestión jurídica respecto de la cual se solicita la opinión del TPR, las razones que motivan la solicitud y los preceptos normativos del MERCOSUR relacionados con la cuestión planteada. En el caso de los dictámenes solicitados por los tribunales superiores con jurisdicción nacional de un Estado miembro, la cuestión jurídica a ser consultada al TPR debe plantearse dentro de un proceso pendiente.

EI TPR tiene cuarenta y cinco días para emitir su dictamen interpretativo. Este plazo se puede suspender cuando lo estime necesario el TPR para solicitar aclaraciones o documentos del solicitante. Para la suspensión el PO no ha fijado plazo ${ }^{164}$.

Aunque las opiniones consultivas no tienen carácter vinculante, no se puede negar la influencia que pueden llegar a tener al ser dictados por el tribunal que tiene la última palabra respecto de la interpretación de las normas jurídicas del MERCOSUR ${ }^{165}$. La influencia de tales dictámenes interpretativos se verá fortalecida con la obligación de publicarlos en el Boletín Oficial del estado del MERCOSUR, lo que además facilitará la invocación de los derechos subjetivos que eventualmente se puedan derivar de la interpretación de la normativa aprobada en el MERCOSUR que se haga a través de las opiniones consultivas del TPR.

\section{4) Justificación del Procedimiento de Consulta}

En la medida que los tribunales de los Estados miembros apliquen normas del MERCOSUR y estén llamados a determinar si la normativa de Derecho Internacional incorporada en su ordenamiento jurídico, es aplicable directamente y puede ser invocada por las personas, existe el riesgo que las interpretaciones que haga cada tribunal difieran entre sí. Ello perjudica la seguridad jurídica y la atracción del bloque económico completo, dado que la existencia de interpretaciones divergentes dentro de un mismo Estado miembro o entre órganos judiciales de diferentes Estados miembros significa que las personas no poseen la misma posición en los Estados miembros en relación a la normativa del MERCOSUR ${ }^{166}$. 
El peligro de interpretaciones diferentes no significa sin embargo que las normas aprobadas en el marco del MERCOSUR no deberían ser aplicadas por tribunales de los Estados miembros. Por el contrario, ese es un proceso completamente sano que es consecuente con los objetivos del TA y que contribuye a fomentar el papel de los actores privados en el proceso de integración económica regional. Lo que se quiere decir, es que, la contribución de los órganos judiciales nacionales será aún mayor, si se rige por criterios uniformes en los Estados miembros del MERCOSUR.

Para fomentar la interpretación uniforme, se han establecido mecanismos tales como el procedimiento prejudicial ante el Tribunal de Justicia de las Comunidades Europeas (TJCE) ${ }^{167}$ o el dictamen de la Comisión de Libre Comercio prevista en el marco del NAFTA ${ }^{168}$. En el

Se trata de un procedimiento que se inicia dentro de un proceso judicial pendiente en un Estado miembro de la Unión Europea (UE), a través del cual un tribunal solicita al TJCE una interpretación de alguna norma comunitaria que deba ser aplicada en el proceso en el cual ha sido planteada la cuestión de interpretación. También se pueden plantear a través de este procedimiento cuestiones sobre la validez de normativa de Derecho secundario de la CE. La sentencia de interpretación que sea dictada por el TJCE es vinculante para el tribunal solicitante. Todos los tribunales de los Estados miembros de la UE pueden elevar solicitudes de interpretación, siendo obligatorio plantearlas solo para los tribunales de última instancia.

El procedimiento prejudicial ante el TJCE se inspiró en procedimientos similares de control ejercidos por la jurisdicción constitucional en Alemania e Italia y por su intermedio el TJCE fue desarrollando jurisprudencia que ha sido de capital importancia para considerar hoy en día a las fuentes normativas de la CE como un ordenamiento jurídico en muchos aspectos diferenciado del Derecho Internacional Público general. Hoy ya parece olvidado que los Estados miembros de la entonces denominada CEE defendían precisamente en un procedimiento prejudicial ante el TJCE una interpretación del entonces denominado Tratado de la Comunidad Económica Europea (TCEE) como un tratado regido por la práctica y normas Derecho Internacional Público general Véase SEIDL-HOHENVELDERN/LOIBL (n.92), p. 200 (n. al margen 1373); KUTSCHER, Hans, "Der Gerichtshof der Europäische Gemeinschaften" en Europäische Grundrechte Zeitschrift Vol. 5 (1978), p. 506 y STREINZ (n. 87), p. 5.

La mencionada evolución del Derecho de la CE es improbable en el TLCAN debido a que el mecanismo contemplado para resguardar la uniformidad de la interpretación precisamente busca resguardar las interpretaciones gubernamentales y no aquellas realizadas por un tercero imparcial como sería el TJCE.

En el TLCAN el dictamen de interpretación se origina cuando surge una cuestión de interpretación o aplicación de ese tratado en un procedimiento judicial o administrativo interno que sea considerado por cualquier Estado parte como relevante para solicitar un dictamen interpretativo de la Comisión de Libre Comercio o cuando un tribunal u órgano administrativo de un Estado solicita a este que se eleve dicha solicitud ante la Comisión de Libre Comercio. El hecho que este órgano esté compuesto por representantes de cada Estado parte permite concluir que la interpretación que se acuerde será una interpretación acordada por los respectivos gobiernos, esto es, que privilegie sus puntos de vista. Si no hay acuerdo entre Ios representantes de los Estados parte en la Comisión de Libre Comercio, las diferentes opiniones podrán ser hechas llegar al órgano judicial o administrativo respectivo. Las interpretaciones que resulten de este procedimiento pueden entrar en conflicto con los intereses de un privado cuando por ejemplo, este último quiera hacer valer una interpretación de la normativa del TLCAN que restrinja la actividad de la administración nacional en beneficio de una mayor liberalización comercial. 
MERCOSUR, más de una década después, desde que se acordara el TA, se ha reconocido tácitamente en el Preámbulo del TA la necesidad de que las normas jurídicas del bloque se apliquen de manera uniforme, al reconocer que estas necesitan ser aplicadas "de forma consistente y sistemática" y que esa es la forma de "consolidar la seguridad jurídica". El medio para ello ha sido la creación de un órgano judicial permanente y el procedimiento de consulta contemplados en el PO. Este puede ser considerado como un mecanismo intermedio entre los procedimientos antes mencionados de la CE y el TLCAN. Por un lado se entrega a un tercero imparcial, el TPR, la competencia para emitir opiniones consultivas y hacer interpretaciones de autoridad sobre las fuentes normativas del MERCOSUR. Por otro lado la opinión consultiva no es una sentencia judicial que obligue al tribunal u órgano que la solicitó, como sí es el caso para el tribunal que inicia un procedimiento prejudicial ante el TJCE, con lo que se asimila a la solicitud de interpretación que se hace en el TLCAN. De ese modo no se pasa a llevar una comprensión de la soberanía que considere incompatible con esta el efecto vinculante de las sentencias prejudiciales del TJCE respecto de un órgano judicial nacional, cuestión que en Hispanoamérica tiene un precedente en la ley venezolana aprobatoria del tratado que estableció el Tribunal de Justicia de la Comunidad Andina y que contempla un mecanismo muy similar al procedimiento prejudicial ante el TJCE ${ }^{169}$, la que subrayó las prerrogativas de sus tribunales nacionales, y la reserva hecha por Colombia al mismo tratado, la que sería invalidada posteriormente por la Corte Suprema de ese país ${ }^{170}$.

\section{5) Crítica al Procedimiento de Consulta}

Una crítica al procedimiento de consulta contemplado en el PO podría ser la circunstancia de que las opiniones consultivas no tienen efecto vinculante para el tribunal que las solicita, esto es, las interpretaciones que haga el TPR deben ser aceptadas voluntariamente para que sean aplicadas. Sin embargo, en general los tribunales internacionales carecen de medios para obligar a hacer cumplir sus sentencias ${ }^{171}$, ya que no cuentan con el monopolio estatal de la fuerza para forzar, en caso necesario, el cumplimiento de sus sentencias. Incluso la obligatoriedad

\footnotetext{
169 Ese tratado fue firmado el 28 de mayo de 1979 y modificado mediante el Protocolo Modificatorio el Tratado de Creación del Tribunal de Justicia de la Comunidad Andina de 28 de mayo de 1996. La interpretación prejudicial es contemplada en los Arts. 32-36.

170 MARWEGE, Renata, Der Andergerichtshof - Das Rechtsschutzsystem des Andenpaktes mit vergleichenden Bezügen zum Recht der Europäischen Gemeinschaft (Editorial Duncker \& Humblot, Berlin, 1995) pp. 105-107 y 120-125.

171 Helfer/Slaughter (n. 41), p. 285.
} 
de las sentencias prejudiciales del TJCE descasa sobre medios coercitivos bastante limitados ${ }^{172}$.

La principal debilidad de las opiniones consultivas previstas ante el TPR consiste en que se haya limitado la facultad de solicitar interpretaciones al TPR solo a los tribunales superiores de los Estados miem$\operatorname{bros}^{173}$. La situación opuesta es precisamente una de las principales fortalezas del procedimiento prejudicial del TCE, ya que ante este, cualquier tribunal está facultado para solicitar una sentencia interpretativa. De acuerdo a la experiencia europea, los tribunales superiores han sido más reacios para solicitar sentencias prejudiciales ${ }^{174}$.

La crítica anterior se hace más evidente si se tiene en cuenta que los tribunales internacionales tienen la limitación de que los Estados prefieren resolver sus diferencias por medios diplomáticos, en vez de por medios jurisdiccionales ${ }^{175}$, por lo que tiene menos oportunidades que los tribunales nacionales para recibir casos concretos sobre los que se puedan pronunciar ${ }^{176}$. Esto cambia cuando los individuos tienen acceso a la jurisdicción internacional, ya que estos no hacen las mismas consideracio-

172 En caso de no acatamiento de una sentencia prejudicial por un tribunal de un Estado miembro de UE, debería iniciarse un procedimiento por incumplimiento del TCE contra un Estado miembro de la UE, el cual solo puede ser iniciado por otro Estado miembro o la Comisión Europea, sin perjuicio, que en caso de no acatamiento de la sentencia que condena a un Estado miembro por incumplimiento del tratado, solo desde 1993 existe la posibilidad de aplicar una multa (Art. 228 TCE), cuestión que también dependerá de una solicitud del órgano ejecutivo de la CE. Ello indica que los medios para ejecutar forzosamente las sentencias del TJCE no dependen de él mismo, sino que requieren de la intervención de otro órgano o un Estado miembro, los que antes de actuar harán consideraciones políticas o de oportunidad. En todo caso, el procedimiento para la aplicación de multas no se puede asimilar al monopolio de la fuerza reservado para el Estado. Véase PERNICE, Ingolf, "Die Dritte Gewalt im europäischen Verfassungsrecht" en Europarecht, Vol. $31 \mathrm{~N}^{\circ} 1$ (1996), p. 38.

173 Art. 2 RPO.

174 Por ejemplo, un setenta y cinco por ciento de los procedimientos prejudiciales fueron solicitados en 1998 por tribunales de instancias inferiores, cifra que se manejaba antes de realizarse la última reforma a los tribunales de la CE por medio del Tratado de Niza. $C f r$. VV.AA. Informe del Grupo de Reflexión sobre el Futuro del Sistema Jurisdiccional de las Comunidades Europeas (en línea) [fecha de consulta: 4 de septiembre de 2006], http:// ec.europa.eu/comm/dgs/legal_service/docs/due_es.pdf (p. 18) Asimismo, han ido los tribunales superiores los que han recurrido a la doctrina del acte clair, para negar la obligación de solicitar sentencias interpretativas al TJCE. La "claridad" la han determinado afirmando que no existe duda sobre la validez o interpretación del Derecho de la CE en casos concretos, con lo cual se ha negado la obligación de platear la cuestión de interpretación o validez. Cfr. DAUSES (n. 87), p. 162 y EHRICKE, Ulrich, Die Bindungswirkung von Urteilen des EuGH im Vorabentscheidungsverfahren nach deutschem Zivilprozessrecht und nach Gemeinschaftsrecht (Europa-Institut, Univ, des Saarlandes, Saarbrücken, 1997), p. 16. Helfer/ Slaughter (n. 41), pp, 285-286, MalanCZuK (n. 100), p. 412, OppermanN, Thomas. Europarecht - Ein Studienbuchl (Editorial Beck, Munich, 1999), p. 43 y ORREGO VICUÑA (n. 122), p. 96.

176 EVERLING, Ulrich, Richterrecht in der Europäischen Gemeinschaft, (Europa-Institut, Univ. des Saarlandes, Saarbrücken, 1997), p. 49. 
nes que los Estados al momento de recurrir a un tribunal. Ejemplo de ello son el Tribunal Europeo de Derechos Humanos (TEDDHH) y el TJCE, los que al ser comparados internacionalmente son considerados los tribunales internacionales más activos y exitosos ${ }^{177}$, sin perjuicio de las diferencias que hay entre ellos en sus competencias y atribuciones ${ }^{178}$.

Al TPR los individuos no pueden hacer llegar sus demandas, tampoco los órganos, solo los Estados miembros del MERCOSUR. Al contemplarse en el PO el procedimiento de consulta, era posible pensar que se permitiría el acceso directo a todos los tribunales de los Estados miembros a este procedimiento, de manera que incluso los tribunales de primera instancia pudiesen solicitar opiniones consultivas. Sin embargo, el RPO limitó dicha facultad a los tribunales superiores. Con ello se limitó las posibilidades de que el TPR asumiese un rol más activo e influyente respecto de la interpretación y aplicación uniforme de las fuentes normativas del MERCOSUR, dado que muchas cuestiones de interpretación sobre las fuentes normativas mencionadas que se planteen en casos concretos que deban ser resueltos por tribunales inferiores de los Estados miembros, no podrán ser planteadas al TPR en forma de una solicitud de opinión consultiva, sino hasta que el caso sea conocido por un tribunal superior.

$\mathrm{Al}$ restringir la solicitud de opiniones consultivas se debilita el papel del TPR en el desarrollo de una interpretación y aplicación similar en todos los Estados miembros del MERCOSUR de las normas creadas para regir en todo el territorio del bloque económico. En la medida que menos sean los potenciales solicitantes de dictámenes interpretativos se restringe el desarrollo de una jurisprudencia de interpretación de las normas del MERCOSUR en base a consultas de tribunales nacionales que sería potencialmente útil para todos los tribunales que deban interpretar y aplicar las mismas fuentes normativas del MERCOSUR en casos similares. Dicha jurisprudencia permitiría acelerar un proceso lento que consiste en el desarrollo de métodos de interpretación comunes por parte de las jurisdicciones nacionales de los Estados miembros, los que no solo se deberían basar en el Derecho Internacional, sino que también en los

177 WÜHLER, Norbert/SEIdL-HohEnVeldern, Ignaz, "Internationale Gerichtsbarkeit" en Lexikon des Rechtes/Völkerrecht (Editorial Luchterhand, Neuwied, Kriftel, Berlín, 2001), p. 141 .

178 La jurisdicción del TJCE fue desde sus inicios establecida sin límites temporales, en cambio en el caso del TEDDHH la competencia para decidir sobre demandas individuales, no así las interestatales, debía ser concedida por los Estados parte de la Convención Europea de DDHH (CEDDHH), los cuales la reconocían limitada en el tiempo. Ello cambió con la entrada en vigencia del Protocolo n. 11 de la CEDDHH, de acuerdo al cual no se requiere un reconocimiento expreso de la jurisdicción del TEDDHH respecto de las demandas individuales. Cfr. OPPERMANN (n. 123), pp.42-44. 
propios métodos de interpretación de los jueces nacionales, los que por su naturaleza resultarían más idóneos en aquellas relaciones jurídicas donde están involucradas personas y que a la vez constituirían una base común de tradiciones y métodos jurídicos que favorecería su aceptación en los Estados miembros ${ }^{179}$. El desarrollo de esos métodos de interpretación uniformes puede ser llevado a cabo por tribunales nacionales y la doctrina a través de las colecciones jurisprudenciales, revistas especializadas, el contacto directo entre los jueces y la publicación de las sentencias en Internet ${ }^{180}$, pero no cabe duda, a partir de la experiencia del TJCE con el procedimiento prejudicial, que el mencionado proceso sería más rápido si la participación del TPR fuese mayor. Por la naturaleza del procedimiento de consulta, el TPR se convertiría en un "punto de encuentro" para la doctrina y jurisprudencia nacionales sobre dichas materias, sin perjuicio de que estaría en un lugar privilegiado como órgano y tribunal permanente del MERCOSUR.

\section{6) Perspectivas del Procedimiento de Consulta}

En las condiciones actuales este procedimiento contribuirá al desarrollo de una interpretación y aplicación uniforme de las normas del MERCOSUR en los Estados miembros si las opiniones consultivas son fundadas y redactadas muy bien, con el fin de que cumplan una función didáctica y de persuasión para extraer métodos interpretativos comunes. Por ello es que debería usarse de manera muy cuidadosa la posibilidad de emitir votos disidentes dentro de dichos dictámenes interpretativos ${ }^{181}$. Es cierto que las opiniones disidentes tienen la ventaja de favorecer la claridad argumentativa, ya que evitan que se emitan opiniones consultivas "estratégicamente ambiguas" y que demuestren solo el mínimo común denominador entre sus miembros ${ }^{182}$. Sin embargo, es muy probable que opiniones divergentes entre los miembros del TPR restaran autoridad a las opiniones consultivas ${ }^{183}$ y que por ahora ${ }^{184}$ tiene solo cinco jueces, número que no impide alcanzar acuerdos para hacer una interpretación de autoridad ${ }^{185}$.

\footnotetext{
179 KLEINHEISTERKAMP (n. 129), Pp. 554-556 y RAMOS (n. 88), p. 88.

180 KLEINHEISTERKAMP (n. 129), pp. 570-571 y SAMTLEBEN "Rechtssystem”(n. 12), pp. 81-82.

181 A diferencia del procedimiento ante el TAH o ante el TPR cuando actúa como tribunal de única instancia o de revisión.

182 Helfer / Slaughter (n. 41), p. 327.

183 Véase supra III 2.2)

184 Ya hemos mencionado que el ingreso de Venezuela como miembro del MERCOSUR probablemente tendrá como consecuencia el cambio en el número de integrantes de los órganos del bloque. Véase nota a pie de pág. n. 35. 


\section{Conclusiones}

La solución de controversias en el MERCOSUR se ha caracterizado por una constante evolución. Todo indica que seguirá desarrollándose, dado que el último tratado que regula sus procedimientos deja abierta la posibilidad de futuras modificaciones. Desde muy temprano se contempló el recurso al arbitraje obligatorio, sin perjuicio de que por varios años se utilizó casi exclusivamente el informal procedimiento de consulta para la solución de sus controversias. Asimismo, se contemplo la posibilidad de que los particulares reclamen contra las normas de otros Estados miembros que los perjudique o puedan perjudicar. Se trata de un procedimiento que para prosperar, requiere del concurso del Estado donde se resida habitualmente o se tiene la residencia comercial. Sin embargo, es un reconocimiento de que las normas del MERCOSUR buscan facilitar la actividad económica de los privados en el territorio de todos los Estados parte.

La convocatoria del primer TAH inició una nueva etapa en la solución de las controversias entre los Estados miembros, a partir de la cual se ha desarrollado una jurisprudencia arbitral relevante para determinar los compromisos asumidos por los Estados que suscribieron el TA y la función de los tribunales del MERCOSUR. Especialmente importante son los laudos que han ido restringiendo la discrecionalidad de los Estados miembros para establecer restricciones no arancelarias al comercio y para incorporar en los ordenamientos jurídicos nacionales las normas del MERCOSUR.

Otro aspecto a considerar cuando se estudian los procedimientos de solución de controversias del MERCOSUR es la labor de los jueces nacionales para determinar cuándo las normas de dicho bloque son selfexecuting y cuándo además pueden ser invocadas por particulares respecto de las Administraciones nacionales o de otras personas. Los resultados de esta actividad jurisdiccional determinan en gran medida los márgenes de acción para los actores económicos privados en el proceso de integración económica.

El mayor aporte del PO es la creación del TPR. Este ha sido concebido para mantener la coherencia de la jurisprudencia arbitral del MERCOSUR. Además se contempla la posibilidad de solicitar opiniones consultivas al TPR por parte de los tribunales nacionales superiores con jurisdicción nacional. Con ello se ha reconocido la necesidad de que la coherencia de la interpretación de las normas del MERCOSUR no se debe limitar al ámbito externo, sino que también importa cuando los intérpretes son los jueces nacionales. Sin embargo, al haber facultado solo a los tribunales nacionales superiores como los únicos tribunales nacionales que pueden solicitar dictámenes de interpretación, se ha restringido la utilidad del procedimiento de consulta como medio para potencias la 
interpretación y aplicación uniforme de las normas del MERCOSUR. Ello no quita que cuando se solicite una opinión consultiva al TPR, este cumpla con mucha responsabilidad dicha función.

\section{BIBLIOGRAFÍA CONSULTADA}

- Almeida Mello, Leonel Itaussu, Brasil y Argentina en perspectiva: competencia, distensión e integración, pp. 291-302 (en línea). [fecha de consulta: 28 de junio de 2006]. Disponible en: <http:// 168.96.200.17/ar/libros/filopol2/mello.pdf>

- Alonso García, Ricardo, Tratado de Libre Comercio, Mercosur y Comunidad Europea - Solución de controversias e interpretación uniforme (McGraw-Hill, Madrid, 1997).

- Alter, Karen J., "Who are the 'Masters of the Treaty'?: European Governments and the European Court of Justice" en Internacional Organization Vol. 52 n. 1 (1998).

- BAARS, Alf, "Kommentar zum 3. Schiedsspruch" en BASEDOW, Jürgen/ SAMTLEBen, Jürgen (eds.), Wirtschaftsrecht des MERCOSUR Horizont 2000, Baden-Baden, 2002.

- Bernhard, Rudolf, "Vertragsauslegung" en SeIdL-HohenvelDERN, Ignaz (ed.), Lexikon des Rechts Völkerrecht (Ed. Luchterhand, Neuwied, Kriftel, 2001, $3^{\mathrm{a}}$ ed.).

- Consejo ARgentino para las Relaciones internacionales (CARI)/ FKA, Taller de Reflexión "Solución de Controversias en el Mercosur: Evaluación y Propuestas" Análisis de los tres primeros laudos (CARI/FKA, Buenos Aires, 2000).

- DAuses, Manfred A., Das Vorabentscheidungsverfahren nach Artikel 177 EG-Vertrag (Ed. Beck, Munich, 1995).

- Díaz Pereira, Ramón, Protocolo de Olivos: algunas reflexiones sobre los institutos que deben ser objeto de reglamentación específica en "Cuaderno de NEGOCIOS Internacionales e Integración" Vol. VIII n. 36-40 (2002).

- Dreyzin De Klor, Adriana, "El Reglamento del Protocolo de Olivos - Algunas anotaciones" en Revista Latinoamericana de Derecho Año II, n. 3 (2005).

- EHRICKE, Ulrich, Die Bindungswirkung von Urteilen des EuGH im Vorabentscheidungsverfabren nach deutschem Zivilprozessrecht und nach $\mathrm{Ge}_{\text {- }}$ meinschaftsrecht (Europa-Institut, Univ. des Saarlandes, Saarbrücken, 1997).

- Ekmekdjian, Miguel Angel, “¿Una Constitución para el Mercosur?" en Anuario de Derecho Constitucional Latinoamericano. (1999).

- EVERLING, Ulrich, Richterrecht in der Europäischen Gemeinschaft (Europa-Institut, Univ. des Saarlandes, Saarbrücken, 1997).

- Filho, Calixto / SAmtleben, Jürgen; "Der Südamerikanische Gemeinsame Markt. Eine rechtliche Analyse des MERCOSUR. Teil I", 
Wertpapier Mitteilungen - Zeitschrift für Wirtschafts - und Bankrecht, Nr. 33 (1992).

- FISCHER, Thomas, "MERCOSUR - Eine Zwischenbilanz" en Bendel, Petra/ Fischer, Thomas (eds.), Wie erfolgreich ist der MERCOSUR? Das südamerikanische Bündnis aus interdisziplinärer Sicht (Verlag für Entwicklungspolitik, Saarbrücken, 1999).

- Fundación KonRad Adenauer (FKA) / Secretaría del MERCOSUR (eds.), Primer Informe sobre la Aplicación del Derecho del MERCOSUR por los Tribunales Nacionales (2003) (FKA, Berlín, Montevideo, 2005).

- FKA/ Secretaría del MERCOSUR (eds.), Segundo Informe sobre la Aplicación del Derecho del MERCOSUR por los Tribunales Nacionales (2004) (FKA, Oficina Uruguay y Secretaría del MERCOSUR, Montevideo, 2006).

- GARNELO, Vicente, Evolución institucional y jurídica del MERCOSUR (BID-INTAL, Buenos Aires, 1997).

- Gratius, Susanne, "Warum stagniert der Mercosur? Die politischinstitutionelle Dimension der Krise", en Lateinamerika Analysen 1 (2002).

- Halperin, Marcelo, "Los Particulares y el MERCOSUR: el Protocolo de Brasilia para la solución de controversias" en Integración Latinoamericana, Vol. $17 \mathrm{Nr} .178$ (1992).

- Helfer, Laurence R./Slaughter, Anne-Marie, "Toward a Theory of effective Supranational Adjudication" en Yale Law Journal, Tomo $107 \mathrm{~N}^{\circ} 2$ (1997).

- Hilf, Meinhard/ OETER, Stefan, WTO-Recht - Rechtsordnung des Welthandels (Ed. Nomos, Bade-Baden, 2005).

- Irigoin Barrenne, Jeannette, "La Convención Americana de Derechos Humanos como derecho interno chileno" en INFANTE CAFFI, María Teresa / CAVE SCHNÖHR, Rose, Solución judicial de controversias: el derecho internacional ante los tribunales internacionales $e$ internos (Universidad de Chile, Santiago, 1995).

- Kleinheisterkamp, Jan, "Seguridad Jurídica en el MERCOSUR: $\mathrm{La}$ interpretación uniforme del derecho comunitario" en Revista de Derecho Privado y Comunitario (2000-1).

- Kutscher, Hans, "Der Gerichtshof der Europäische Gemeinschaften" en Europäische Grundrechte Zeitschrift Vol. 5 (1978).

- LaVranos, Nikolaus, "An Introduction into the Regional Economic Integration Process of the Ameritas" en Zeitschrift für europarechtliche Studien, Vol. 4 n. 1 (2001).

- MalanczuK, Peter, "Einvernehmliche Streitbeilegung" en Lexikon des Rechtes/Völkerrecht (Ed. Luchterhand, Neuwied/ Kriftel, 2001).

- MANCINI, G. Federico, "The Making of a Constitution for Europe" en Common Market Law Review Vol. 26 n. 4 (1989). 
- Marwege, Renata, Der Andergerichtshof - Das Rechtsschutzsystem des Andenpaktes mit vergleichenden Bezügen zum Recht der Europäischen Gemeinschaft (Editorial Duncker \& Humblot, Berlin, 1995).

- Montt Oyarzún, Santiago, "Aplicación de los Tratados Bilaterales de Protección de Inversiones por Tribunales Chilenos. Responsabilidad del Estado y Expropiaciones Regulatorias en un Mundo Crecientemente Globalizado" en Revista Chilena de Derecho Vol. 32 n. 1 (2005).

- Naciones Unidas - CEPAL, 2004 Anuario Estadístico de América Latina y el Caribe (Naciones Unidas, Santiago de Chile, 2005).

- Nohlen, Dieter; Fernández Baeza, Mario, "Cooperación y Conflicto. Concepto y procesos en la Cuenca del Plata" en NOHLEN, Dieter et al. (eds.), Kooperation und Konflikt im La Plata-Becken, (Breitenbach, Saarbrücken, 1986).

- NoHlen, Dieter /FERnÁndeZ BAeZA, Mario, "Die Entwicklung der argentinisch-brasilianischen Beziehungen in den 70er Jahren: vom Konflikt zur Kooperation" en NoHLEN, Dieter et al. (eds.), Kooperation und Konflikt im La-Plata-Becken, (Breitenbach, Saarbrücken, 1986).

- Nood Taquela, María Blanca, "Solución de Controversias en el Mercosur" en Jurisprudencia Argentina, Tomo III (1997).

- Oellers-Frahm, Karin, "Probleme und Grenzen der obligatorischen internationalen Gerichtsbarkeit", en Archiv des Völkerrechts, Tomo 27 (1989).

- Olivares Tramón, José Miguel/ Tüllmann, Norbert "Die künftige Gestaltung der EU-Gerichtsbarkeit nach dem Vertrag von Nizza" en Neue Zeitschrift für Verwaltungsrecht, $\mathrm{N}^{\circ} 1$ (2004).

- OPPERMANN, Thomas. Europarecht - Ein Studienbuchl (Editorial Beck, Munich, 1999).

- OpertTi BADÁN, Didier, "Sistema de resolución de controversias en el MERCOSUR" en KLEINHEISTERKAMP, Jan/ LORENZO IDIARTE, Gonzalo A. (coords.), Avances del derecho internacional privado en América Latina - Liber Amicorum Jürgen Samtleben, Montevideo, 2002.

- OrRego VicuÑA, Francisco, "Análisis de la práctica latinoamericana en materia de solución de controversias durante la década de 1970 y sus implicaciones para el futuro" en ORREGo VICUÑA, Francisco/ Irigoin Barrene, Jeannette (eds.), Perspectivas del derecho internacional contemporáneo y visión de América Latina Tomo II (Ed. Universitaria, Santiago de Chile, 1981).

- PASTORI, Alejandro, Los regímenes de solución de controversias en el marco de la ALADI y su articulación con otros sistemas de solución de controversias, en particular el existente en la OMC en VIII Seminario Jurídico: "La Dimensión Jurídica de la Integración" celebrado el 2 y 3 de octubre de 2003 en Rosario, Argentina (en línea). 2 de octubre de 2003 [fecha de con- 
sulta: 13 noviembre 2006]. Disponible en: http://www.aladi.org/nsfala$\mathrm{di} /$ reuniones.nsf/6053654be $7953 \mathrm{f} 91032569 \mathrm{fa} 0064855 \mathrm{~b} /$ 0b286a2719a2287703256ebb006988bc?OpenDocument

- Pena, Celina/ Rozemberg, Ricardo, Una aproximación al desarrollo del MERCOSUR: sus fortalezas y debilidades (BID-INTAL, Buenos Aires, 2005).

- PeÑA, Felix, Mercosur: Análisis de una Década y Tendencias hacia el Futuro (en línea). Mayo de 2001 [fecha de consulta: 30 de junio de 2006]. Disponible en: http://webudesa.udesa.edu.ar/departamentos/ economia/mariano_tommasi/cedi/dts/dt50.PDF

- PReusse, Heinz, "Warum stagniert der MERCOSUR? Wirtschaftliche Faktoren" en Lateinamerika Analysen 1 (2002).

- PuCeiro Ripoll, Roberto, "El Protocolo de Olivos y el Régimen de Solución de Controversias del MERCOSUR" en Cuaderno de NEGOCIOS Internacionales e Integración Vol. VIII n. 36-40 (2002).

- Puceiro Ripoll, Roberto, "El Protocolo de Olivos y el Régimen de Solución de Controversias del MERCOSUR" en Cuaderno de NEGOCIOS Internacionales e Integración Año VIII, $\mathrm{n}^{\circ}$ 36-40 (2002), p. 15 .

- Ramos, Dante Marcelo, "Protección jurídica para los particulares en el MERCOSUR" en Contribuciones n ${ }^{\circ} 1$ (1999).

- RUdolf, Walter, "innerstaatliches Recht und Völkerrecht" en SEIDL-HOHENVELDERN, Ignaz (ed.),Lexikon des Rechtes/Völkerrecht.

- SAmtleben, Jürgen, "Der MERCOSUR als Rechtssystem" en BASEDOW, Jürgen/ SAMTLEBEN, Jürgen (eds.), Wirtschaftsrecht des MERCOSUR - Horizont 2000, Baden-Baden, 2002.

- Samtleben, Jürgen, "Las Perspectivas para un Tribunal del MERCOSUR y la experiencia europea" en Jurisprudencia Argentina, Tomo I (1998).

- Samtleben, Jürgen, "Erster Schiedsspruch im Mercosur wirtschaftliche Krise als rechtliche Herausforderung?" en Europäische Zeitschrift für Wirtschaftsrecht, Nr. 3 (2000).

- Santalla Vargas, Elizabeth/ Sennekamp, Andreas, "Streitschlichtung als Integrationsfaktor in der Europäischen Union und im MERCOSUR" en Recht der Internationalen Wirtschaft, $\mathrm{n}^{\circ} 4$ (2002).

- Sartori, Marta Susana, "Laudo del Tribunal Ad Hoc del Mercosur en la controversia sobre subsidios a la producción y exportación de carne de cerdo" en Rey Caro, Ernesto/ Drnas de Clément, Zlata (eds.), Doctrina Jurisprudencial de los Laudos Arbitrales del MERCOSUR (Instituto de Derecho Internacional y Derecho de la Integración, Córdoba, 2004).

- SCHIRM, Stefan A., Globale Märkte, nationale Politik und regionale Kooperation in Europa und den Amerika (Nomos, Baden-Baden, 1999. 
- SCHIRM, Stefan A., Kooperation in den Amerikas: NAFTA, MERCOSUR und die neue Dynamik regionaler Zusammenarbeit (Nomos, Baden-Baden, 1997).

- SeIdL-HohenVeldern, Ignaz /STeIn, Torsten, Völkerrecht (Heymanns, Colonia, Berlin. Bonn, Munich, 2000).

- SteIn, Eric, "Lawyers, Judges and The Making of a transnacional Constitution" en American Journal of Internacional Law Vol. 74 n. 1 (1981).

- StreinZ, Rudolf, Europarechty (Ed. C.F. Müller, Heidelberg, 2001).

- TACCONE, Juan Josél Nogueira, Uziel (eds.), Informe MERCOSUR $N^{\circ} 6$ Período 1999-2000 (BID-INTAL, Bs. Aires, 2000).

- TACCONe, Juan Josél Nogueira, Uziel (eds.), Informe MERCOSUR $N^{o} 7$ Período 2000-2001 (BID-INTAL, Bs. Aires, 2001).

- TACCONE, Juan Josél NOGUEIRA, Uziel (eds.), Informe MERCOSUR $N^{o} 8$ Período 2001-2002 (BID-INTAL, Bs. Aires, 2003).

- TACCONe, Juan Josél Nogueira, Uziel (eds.), Informe MERCOSUR $N^{\circ} 8$ Período 2001-2002 (BID-INTAL, Bs. Aires, 2003).

- TAYLOR, Cherie O'Neall, "Dispute Resolution as a Catalyst for Economic Integration and a Agent for Deeping Integration: NAFTA and MERCOSUR?" en Northwestern Journal of International Law and Business, Vol. 17, $\mathrm{n}^{\circ}$ 2/3 (1996).

- Then De LAmmerskötTer, Rosario, "Kommentar zum 2. Schiedsspruch" en: BASEDOW, Jürgen/ SAMTLEBEN, Jürgen (eds.), Wirtschaftsrecht des MERCOSUR - Horizont 2000, Baden-Baden, 2002.

- VV.AA. Informe del Grupo de Reflexión sobre el Futuro del Sistema Jurisdiccional de las Comunidades Europeas (en línea) [fecha de consulta: 4 de septiembre de 2006], http://ec.europa.eu/comm/dgs/ legal_service/docs/due_es.pdf.

- Verdross, Alfred/ SimmA, Bruno, Universelles Völkerrecht - Theorie und Praxis (Duncker und Humboldt, Berlin, 1984).

- WeHNER, Ulrich, Der Mercosur - Rechtsfragen und Funktionsfähigkeiten eines neuartigen Integrationsprojektes und die Erfolgsaussichten der interregionalen Kooperation mit der Europäischen Union, (Nomos, Baden-Baden, 1999).

- Wolf-Niedermaier, Anita, Der Europäische Gerichtshof zwischen Recht. und Politik (Ed. Nomos, Baden-Baden, 1997).

- WÜHLer, Norbert/SeIdL-HoHenVeldern, Ignaz, "Internationale Gerichtsbarkeit" en Lexikon des Rechtes/Völkerrecht (Editorial Luchterhand, Neuwied, Kriftel, Berlín, 2001). 